Florida International University FIU Digital Commons

7-21-1999

\title{
Omnivory and periphyton mats: uncoupling and quantifying consumer effects in the Florida Everglades
}

Pamela Geddes

Florida International University

DOI: $10.25148 /$ etd.FI15101547

Follow this and additional works at: https://digitalcommons.fiu.edu/etd

Part of the Biology Commons

\section{Recommended Citation}

Geddes, Pamela, "Omnivory and periphyton mats: uncoupling and quantifying consumer effects in the Florida Everglades" (1999). FIU Electronic Theses and Dissertations. 3585.

https://digitalcommons.fiu.edu/etd/3585 


\title{
FLORIDA INTERNATIONAL UNIVERSITY
}

\author{
Miami, Florida
}

\section{OMNIVORY AND PERIPHYTON MATS: UNCOUPLING AND QUANTIFYING CONSUMER EFFECTS IN THE FLORIDA EVERGLADES}

A thesis submitted in partial fulfillment of the

\author{
requirements for the degree of \\ MASTER OF SCIENCE \\ in \\ BIOLOGY
}

by

Pamela Geddes

1999 
To: Dean Arthur W. Herriott

College of Arts and Sciences

This thesis, written by Pamela Geddes, and entitled Omnivory and Periphyton Mats: Uncoupling and Quantifying Consumer Effects in the Florida Everglades, having been approved in respect to style and intellectual content, is referred to you for judgement.

We have read this thesis and recommend that it be approved.

Sue Perry

Jennifer Richards

Joel C. Trexler, Major Professor

Date of Defense: July 21, 1999

The thesis of Pamela Geddes is approved.

Dean Arthur W. Herriott College of Arts and Sciences

Dean Richard L. Campbell Division of Graduate Studies

Florida International University, 1999 


\section{DEDICATION}

I dedicate this thesis to my parents, Nichú Amorín and Raúl Geddes. Without their love, support, and encouragement this work could not have been possible. 


\section{ACKNOWLEDGMENTS}

I would like to express my gratitude to my major professor, Joel Trexler, for his guidance, encouragement, and unconditional support throughout my research.

My committee members, Jennifer Richards and Sue Perry, provided valuable feedback and insight about important aspects of my study.

Many thanks to the people in my lab and others who, in one way or other, helped me enormously; without them this research could not have been possible: Shawna Baker, Sean Coyne, Daniel Dean, Walter DeLoach, Elba Fernández, Susan Frisch, Nora Geddes, Brian Jeffrey, Adrian Jelenszky, Karen Kandl, Mac Kobza, Bill Loftus, Kyoko Nakamura, Xavier Pagan, Joe Pechmann, Tim Rawlings, Paul and Jennifer Rehage, Greg Robbins, Brooke Shamblin, Chris Stevenson, Ryan Taylor, and Cristina Ugarte. I owe special thanks to John Chick for his enormous help with statistics and many other areas of this study. Thanks also to Evelyn Gaiser for many good discussions on several aspects of periphyton dynamics. Daniel Fernández deserves special mention for his support and endless patience.

I also want to thank Keith Condon for providing great assistance with paraffin embedding and pictures of periphyton mats. Dan Childers, Kelsey Downum, Jim Fourqurean and René Herrera kindly let me use some of their laboratory equipment for periphyton processing.

This project was funded by cooperative agreement CA5280-8-9002 between Everglades National Park and Florida International University. I thank Sue Perry for managing these funds. During the Spring ' 99 semester, I was supported by a graduate fellowship granted by the Tropical Biology Program at Florida International University. 


\section{ABSTRACT OF THE THESIS \\ OMNIVORY AND PERIPHYTON MATS: UNCOUPLING AND QUANTIFYING \\ CONSUMER EFFECTS IN THE FLORIDA EVERGLADES}

by

Pamela Geddes

Florida International University, 1999

Miami, Florida

Professor Joel C. Trexler, Major Professor

The role of omnivores in structuring communities is poorly understood. I studied the effect of two abundant omnivores, grass shrimp (Palaemonetes paludosus) and eastern mosquitofish (Gambusia holbrooki), on periphyton biomass of the Florida Everglades. I performed field experiments to test for consumer top-down and "complex" top-down effects on periphyton biomass. My experiments suggested that shrimp and mosquitofish had consumptive effects on periphyton but in many instances, periphyton wet weight, AFDM, and chlorophyll a increased significantly with shrimp or fish density, suggesting compensation by nutrient regeneration or trophic cascade processes. I propose that characteristic periphyton mat structure and integrity deters herbivory and affects the outcome of the periphyton-consumer interaction. Results from a descriptive study and a laboratory experiment support this hypothesis. Overall, consumption by shrimp and mosquitofish was significant, but coupled with and sometimes compensated by "complex" top-down effects, making these consumers "functional" omnivores. 


\section{TABLE OF CONTENTS}

CHAPTER

INTRODUCTION... 1

METHODS 6

Study site 6

Overview of experimental protocol for field studies 7

Preliminary experiment 10

Wet season experiment 10

Dry season experiment 11

Cross sections of periphyton mats 12

Laboratory experiment 12

Statistical analyses 13

RESULTS 17

Preliminary experiment 17

Wet season experiment 18

Dry season experiment 20

Power analyses and effect size 21

Cross sections of periphyton mats 21

Laboratory experiment 22

DISCUSSION 23

Consumer effects on periphyton 23

Effect sizes and interpretation of field experiments 29 
Consumer-periphyton dynamics in the Everglades:

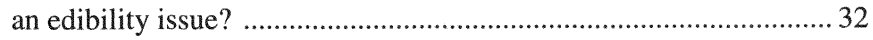

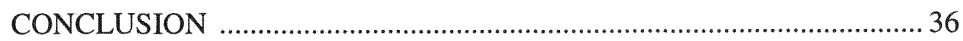

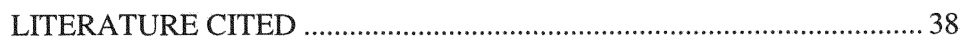

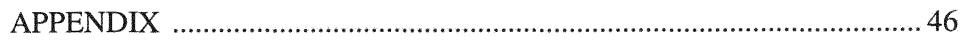




\section{LIST OF TABLES}

TABLE

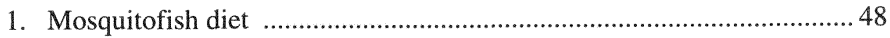

2. Descriptive summary of field experiments ............................................ 49

3. Site descriptions for field experiments ……......................................... 50

4. Summary of treatments for the field experiments .................................. 51

5. ANOVA tables for the Preliminary experiment ................................... 52

6. T-test statistics for the Wet and Dry season experiment ........................ 53

7. Mean periphyton proportion change in cages and bags for

Wet season experiment …................................................................. 54

8. ANOVA tables for Wet season experiment ……….............................. 55

9. Mean periphyton proportion change in cages and bags for

Dry season experiment ……………................................................. 56 


\section{LIST OF FIGURES}

FIGURE

1. Predicted scenarios for the outcome of periphyton-consumer interactions .58

2. Location of study sites 60

3. Preliminary experiment least-square means .62

4. Least-square means for bags and cages; Wet season experiment .64

5. Wet season experiment; shrimp density effects 66

6. Wet season experiment; mosquitofish density effects 68

7. Least-square means for bags and cages; Dry season experiment .70

8. Dry season experiment; consumer density effects .72

9. Power analyses for the Preliminary experiment 74

10. Power analyses for the Wet season experiment .76

11. Power analyses for the Dry season experiment 78 


\section{LIST OF PLATES}

PLATE

PAGE

1. Calcite encrustation and macrophytes in periphyton mats ..................... 80

2. Overall structure of a periphyton mat ............................................... 82

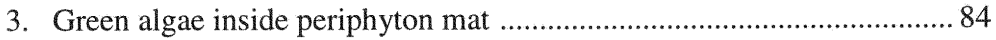

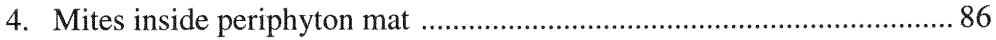

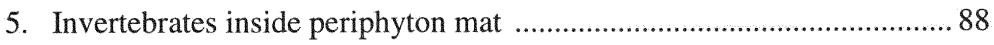

6. Diatoms inside periphyton mat ............................................................ 90 


\section{Introduction}

Regulation of community structure by way of trophic interactions is one possible mechanism that determines the abundance of organisms and the distribution of their biomass at different compartments of food webs. Grazing is an example of such a trophic interaction by which consumers remove primary producer biomass in both terrestrial and aquatic systems. Many omnivores consume both animal and plant biomass, so the term consumer in a grazing context can refer to a strict herbivore or to an omnivore that includes plant material in its diet. Omnivory increases food web connectance, links compartments within the food web and facilitates flow among them, and therefore increases its complexity (Polis 1991, Polis and Strong 1996). The role of omnivores in structuring communities, however, is still poorly understood and needs experimental testing (Polis and Strong 1996, Morin and Lawler 1996). Community dynamics and trophic linkage are not necessarily correlated, so there is a need to establish the importance and ubiquity of omnivory effects on food web structure (Polis 1991, 1994). Studies must go beyond simple cataloging of omnivory (i.e., just stating who eats what and drawing a myriad of connecting arrows), to establish the role played by omnivorous consumers on the dynamics and regulation of a specific prey.

Consumers can affect their prey in more complex ways than by simple top-down, consumptive effects. In particular, two other mechanisms--nutrient regeneration and physical stimulation or physical disturbance--are important because, contrary to top-down effects, they can enhance primary producer biomass. Because these effects are exerted in a top-down manner but affecting availability of resources to the primary producers 
(bottom-up mechanism), I will collectively refer to these stimulatory effects as "complex" top-down effects. "Complex" top-down effects have been studied extensively in terrestrial systems (e.g., Mc Naughton 1979, 1983, 1985, 1986, Owen 1980, Paige and Whitham 1987, but see Belsky et al. 1993), but are lagging behind in aquatic systems. Nutrients regenerated by aquatic grazers can alter the supply and nature of nutrients to primary producers (Lehman and Scavia 1982, Sterner 1986, Sterner 1990, Elser et al. 1988, Vanni 1996, Vanni et al. 1997) and can therefore increase or enhance the biomass of primary producers (algae). Stimulation of algal cells thorough gut passage (Porter 1973) could also be an important process that leads to enhancement of primary producer biomass. Physical stimulation by aquatic consumers could also enhance algal biomass, by differentially increasing resource availability to some cells. Examples of physical stimulation are removal of sediments that leads to increase of light availability (Power 1990, Pringle et al. 1993, Pringle and Blake 1994), removal of epiphytes on other algae (Kupferberg 1997), and mechanical disturbance (even from grazing) that disrupts algal mats and increases light and nutrient availability to remaining cells (McCormick 1994, Steinman 1996). Therefore, it is possible that top-down effects become coupled with "complex" top-down effects and act simultaneously to affect the outcome of consumerresource interactions. "Complex" top-down effects can be substantial and thus should be considered as potentially important processes when testing for consumer effects on their resources.

Edibility of resources could have disproportionate importance in determining outcomes of food-web interactions (Porter 1973, 1977, Leibold 1989, Polis and Strong 1996, Steinman 1996), and therefore should be incorporated in experimental studies that 
address consumer-resource dynamics. Protection mechanisms (toxicity, unpalatability, growth-habits (i.e., morphology) and/or chemical defenses) against consumers are adaptations that confer evolutionary success to those resources that possess them (Otto 1983, Polis and Strong 1996), but they also indirectly confer low fitness to the organisms consuming them. Fitness of consumers is therefore intimately related to the quality of the food they ingest (e.g., Vaughn 1986, Elser et al. 1988, and Agrawal et al. 1999). The evolutionary importance of the link between consumers and the edibility of their resources was emphasized by Leibold's (1989) model, where he defined edibility in terms of the relative contribution of edible versus inedible resources to the consumer's birth rate (the $b_{e}$ and $b_{i}$ terms in his model). Therefore, resistant resources could eventually contribute to the consumer's birth rate, but less so than edible resources, and they might not contribute at all to the consumer's birth rate if they are completely inedible (Leibold 1989). In the model, consumers could also have positive effects on the inedible resources, and Leibold suggested that a likely explanation could involve consumermediated nutrient recycling that differentially affects the inedible algae (Sterner 1990). Another indirect, positive effect could arise from competitive release, where inedible algae respond to reduced abundance of the edible ones due to grazing (Leibold 1989). Thus, it is apparent that resource edibility could mediate and modulate the outcome of the consumer-resource interaction, particularly by affecting the strength of the consumerresource link in food webs.

Quantifying the magnitude of biological effects presents a challenge to experimenters, particularly those that conduct field experiments. In particular, "complex" top-down effects tend to be coupled with top-down effects, therefore making 
it difficult to quantify them. Successful decoupling of the relative roles of consumers can yield important information about animal-periphyton interactions (see Sterner 1986, McCormick 1994, and Vanni and Layne 1997 for different approaches on separation of consumer effects). But more generally, field experiments are prone to suffer from small sample size and high type II error that leads to low power (Polis 1994, Feminella and Hawkins 1995). Experiments with low power provide no capacity to identify cases where grazing is not important, though in evaluating the impact of omnivores the negative result is arguably as important as the positive one. Therefore, it is critical to determine if experimental studies suffer from low power and to explore the causes of such low power. Paramount to this concept is the notion of effect size (e.g., Osenberg et al. 1997) used as the core of experimental design (Mapstone 1996) and not as a simple ancillary metric. Power analyses combined with a firm notion of biologically significant effect sizes permit a clear-eyed assessment of experimental results.

In the Florida Everglades, top-down, consumptive effects on periphyton have been suggested (Hunt 1952, Swift 1981, Browder et al. 1994, but see Rader and Richardson 1992 and Hunt 1961) but have never been tested experimentally. The grass shrimp (Palaemonetes paludosus) feeds primarily on algae but also on macrophytes, detritus and aquatic insects (Hunt 1952, Beck and Cowell 1976, Rader 1994, Havens et al. 1996). The eastern mosquitofish (Gambusia holbrooki) is an omnivorous fish, and periphyton has been reported in its gut contents (Hunt 1952, Stober et al. 1998, Browder et al., in review, A. Jelenszky and J. C. Trexler, unpublished data (Table 1)). The high abundance of periphyton in the Everglades (Hunt 1961, Van Meter-Kasanof 1973, Browder et al. 1982, Swift and Nicholas 1987, Vymazal and Richardson 1995, 
McCormick et al. 1998, Turner et al., in press) along with unusually low consumer densities (Turner et al., in press) makes the Everglades a puzzling system. The high periphyton biomass might be related to its edibility and characteristic mat integrity and structure. This structure might be critical for the grazers' ability to ingest it. The disposition or arrangement of the mats in the Everglades periphyton may hide the edible live material and consumers may not have direct access to it. In addition, I propose that a high content of $\mathrm{CaCO}_{3}$-encrusted algae might deter consumers. These characteristics could potentially make the periphyton mats resistant to herbivory, affecting the outcome of the periphyton-consumer interaction, and e high periphyton biomass.

The purpose of this study was to determine experimentally if mosquitofish and shrimp have any effect (and its nature) on periphyton biomass in the Florida Everglades. In particular, I wanted to assess the significance of omnivore top-down effects as direct consumption, and of "complex" top-down effects as grazer nutrient regeneration and/or physical stimulation effects on periphyton. I chose mosquitofish and shrimp because 1) previous dietary studies have shown they ingest periphyton as part of their omnivorous diet, 2) they comprise the bulk of the fish and invertebrate biomass (30\% and 60\% respectively, estimated from 9 sites across 5 sampling seasons) in Everglades marshes (Turner et al., in press), and 3) they are taxa that are underrepresented in grazing studies (Feminella and Hawkins 1995). Because of these species' high abundance in the Everglades, I hypothesized that even small consumptive effects should be important to the periphyton community.

I conducted three cage experiments in the field to uncouple and quantify the effects of varying omnivore densities on periphyton biomass using a "nested" (sensu 
Vanni and Layne 1997) approach, where porous grazer-exclusion bags were placed inside mesh cages. The bags confined periphyton and allowed nutrients to go thorough, but excluded grazer access. Grazers had free access to periphyton in cages. From this nested design, I predicted several outcomes of periphyton-consumer interactions depending on the type of process I thought was operating in the system (Fig. 1). These predictions provided a conceptual framework to test my hypotheses and interpret my results.

Because I hypothesized that the architecture of the periphyton mat would influence periphyton edibility and affect the outcome of consumer-periphyton interactions, I used a descriptive approach to analyze structural properties and characteristics of the mats by performing cross sections of paraffin-embedded periphyton mats, and I also conducted a laboratory experiment to test for structural effects of periphyton mats on the ability of the consumers to differentially ingest algal taxa.

\section{Methods}

Study site

I conducted field experiments in several areas of the Everglades National Park, Florida, USA (Fig. 2, Table 2), that vary in periphyton characteristics (Table 3), as well as hydroperiod. The term hydroperiod refers to the average time a site is flooded out of a 12-month period (Fennema et al. 1994); therefore, long hydroperiod sites are flooded for more months in a year than are short hydroperiod sites. For the purposes of my study, long hydroperiod sites are defined as sites that remain flooded 6-10 months out of a year, whereas short hydroperiod sites are flooded for 3-5 months out of a year. Generally, long hydroperiod sites have deeper water levels than short hydroperiod sites and have soils 
dominated by peat, whereas soils at short hydroperiod sites are primarily composed of marl (Gunderson 1994). Water levels constrained the choice of sites to conduct my experiments. Therefore, I could test for hydroperiod effects only during the wet season, when both long and short hydroperiod sites had surface water. During the dry season, short hydroperiod marshes dried out and I restricted my experiments to long hydroperiod sites.

\section{Overview of experimental protocol for field studies}

The field experiments were conducted at different times of the year and their duration was slightly different for each experiment (Table 2). I used mesh cages to enclose varying densities of shrimp and mosquitofish with known quantities of periphyton in a full factorial design (Table 2). The cages enclosed an area of $1 \mathrm{~m}^{2}$ and had mesh size of approximately $2 \mathrm{~mm}$; they were closed at the bottom and open at the top. Cages were placed in a row, perpendicular to water flow. In the instances where I used grazer-exclusion bags (Wet season and Dry season experiments), I placed them inside the cages. Bags were $25 \mathrm{~cm}$ in diameter, and approximately $30 \mathrm{~cm}$ long. The opening of the bags floated at the water surface and the actual bag hung into the water column. These bags were specifically designed to exclude shrimp and fish; although grazers did not have access to the periphyton in the bags, their excreted nutrients could pass through the bag mesh $(\sim 1.5 \mathrm{~mm})$. I conducted a simple test to assess the permeability of the bag mesh using food-coloring dye. I placed bags inside a plastic tank (132 $\mathrm{cm}$ in diameter; $56 \mathrm{~cm}$ deep) and I added the dye. The dye passed thorough the mesh readily, suggesting adequate pore size for these experiments. Water flow in the 
Everglades is slow ( $<2 \mathrm{~cm} / \mathrm{sec}$, R. Jones, pers. comm.), so I believe the tanks in which I conducted the dye test approximated conditions in the cages.

The densities of the grazers were varied over three levels $(0$, ambient, and high, equivalent to 0,3 , and 9 mosquitofish, and 0, 20, and 60 shrimp respectively) (Table 4A). These densities reflect natural densities per $\mathrm{m}^{2}$ in Taylor Slough, as obtained by field estimates using throw-trap methods (J. C. Trexler, unpublished data). For mosquitofish, the average density across 10 sampling events between July 1996 and April 1998 was $3 / \mathrm{m}^{2}$, with a range of 1 to 4 (J. C. Trexler, unpublished data). For shrimp, the average density was $18 / \mathrm{m}^{2}$, ranging from 4 to 42 (J. C. Trexler, unpublished data). For the Dry season experiment, mosquitofish densities were raised to 0,5 , and $15(0$, ambient, and high respectively) to better reflect natural densities of the experimental site at Shark Slough (Table 4B). Consumer treatments were randomly assigned to the cages, and if a blocked design was used, treatments were completely randomized within block.

Grazers were collected from Everglades marshes and kept in tanks until the time of the experiment. While in the tanks, the grazers were fed periphyton collected from the field. I measured grazers to the $0.1 \mathrm{~mm}$ at the beginning and end of the experiment to account for growth. I measured standard length for mosquitofish, and carapace length for shrimp. Once the experiment was over, grazers were seined out of the cage, sacrificed using the anesthetic MS-222 and preserved with $10 \%$ formalin. I later transferred them to $70 \%$ ethanol. I also estimated consumer survival in two experiments (Preliminary and Wet season) by averaging survival in individual cages.

The quantity of periphyton added to each cage was constant. I added 2000-2200 $\mathrm{ml}$ (approximately 2300-2400 $\mathrm{g}$ of wet weight) of periphyton to each cage. Bags 
contained $400 \mathrm{ml}(\sim 300 \mathrm{~g}$ wet weight) of periphyton. The combined amounts of periphyton in cages and bags were within the natural biomass range of periphyton found in a $1-\mathrm{m}^{2}$ area in Taylor Slough averaged across 10 sampling events from May 1996 to April 1998 (range: $930.95 \mathrm{ml}$ - $4352.86 \mathrm{ml}$; J. C. Trexler, unpublished data).

Care was taken to standardize the amount and composition of periphyton placed in cages and bags because I hypothesized that the structure and architecture of the periphyton mats might be important to the outcome of my experiments. I collected periphyton mats from the experimental sites with a $0.25-\mathrm{m}^{2}$ seine to drain the excess water, and I weighed it with a Pesola ${ }^{\circledR}$ field scale. I carefully placed the mats on the seine and inside the cages and bags, keeping mat disturbance to a minimum. I obtained wet weights of the mats inside the cages and bags at the beginning and end of each experiment. Wet weight is a good estimate of periphyton biomass for the scale of this experiment, although not a very common measure of biomass in the literature. Power (1991) used "damp weight" of Cladophora, and she reported a good correlation between damp weight and dry weight, a more common measure of biomass. In this study, wet weight was correlated with periphyton volume $\left(R^{2}=0.872 ; n=57 ; \mathrm{Vol}(\mathrm{ml})=0.8673 *\right.$ Wet weight $(\mathrm{g})+143.1)$, and periphyton volume is correlated with AFDM (ash-free dry mass) $\left(R^{2}=0.898, n=15, \ln [\operatorname{AFDM}(\mathrm{g})]=1.2652 * \ln [\mathrm{Vol}(\mathrm{ml})]\right.$; Turner et al., in press). Periphyton samples were taken from each cage and bag both at the beginning and end of the experiment and placed on ice immediately after collection. Upon arrival to the laboratory, they were frozen for later processing. I subsampled for AFDM, chlorophyll a, and total phosphorus (TP), total nitrogen (TN), and total carbon (TC). Samples for AFDM were dried until constant weight at $80{ }^{\circ} \mathrm{C}$ and later ashed in a muffle furnace at 
$500{ }^{\circ} \mathrm{C}$ for one hour following Standard Methods (Eaton et al. 1995). Samples for chlorophyll a were extracted overnight with buffered acetone, and values were determined using a Shimadzu UV-2101PC scanning spectrophotometer (Eaton et al. 1995). Samples for nutrient analyses were sent to the Southeastern Environmental Research Program Nutrient Analysis lab to be processed also following Standard Methods (EPA 365.1 for solids and water, Eaton et al. 1995).

\section{Preliminary experiment}

This experiment was conducted in an area of Taylor Slough characterized by long hydroperiod between February 25 and March 18, 1998 (Fig. 2, Tables 2 and 3). In this experiment, I did not use grazer-exclusion bags, and I did not collect samples for nutrient analyses. All other aspects were described in the previous section.

\section{Wet season experiment}

A large area of the Everglades was inundated during the wet season of 1998, permitting a test of the effect of hydroperiod on grazing effects. Results from the Preliminary experiment suggested "complex" top-down effects so for this experiment I included grazer-exclusion bags containing a known quantity of periphyton. I conducted this experiment between August 10 and August 28, 1998 in three areas of Taylor Slough with adjacent long hydroperiod and short hydroperiod marshes, for a total of 6 study sites (Table 3). This design was chosen to test for hydroperiod effects because water levels allowed me to place cages in spatially paired long and short hydroperiod sites. I used a total of 54 cages ( 3 sets of 9 in short hydroperiod sites, and 3 sets of 9 in long 
hydroperiod sites) (Fig. 2, Table 3). The northernmost site (upstream) was designated as MD (MDS for short hydroperiod and MDL for long hydroperiod). Similarly, the southernmost site was designated TS (TSS and TSL). The intermediate site (halfway in between MD and TS) was designated IM (IMS and IML). I chose long and short hydroperiod sites based primarily on differences between periphyton mats, as well as water levels (Table 3). The short hydroperiod sites had more cohesive and compact mats, dominated by Utricularia cornuta, whereas long hydroperiod sites had periphyton attached to $U$. purpurea, which gave the mats a less cohesive structure (Pechmann et al., in review, pers. obs.). For this experiment, I obtained only one periphyton sample for nutrient analyses at the end of the experiment.

\section{Dry season experiment}

Because of the severity of the dry season in 1999 , which resulted in very low water levels, I could not access Taylor Slough sites to perform this experiment at that time. Therefore, I used a long hydroperiod site in Shark Slough comparable to the long hydroperiod site I used for the Preliminary experiment to conduct this experiment between March 18 and April 12, 1999 (Fig. 2, Table 3). All short hydroperiod areas in the Everglades were dry at this time.

I set up the cages and grazer-exclusion bags within cages in two blocks of 27 cages, placed in rows perpendicular to water flow. Given low survival of grazers in the Wet season experiment due to stressful conditions (see Discussion), I wanted to minimize handling of grazers before the experiment. Thus, I did not measure grazers at the beginning of the experiment, and I only calculated consumer survival for this experiment. 
For this experiment, I obtained periphyton samples for nutrient analyses at the beginning and end of the experiment.

\section{Cross sections of periphyton mats}

To further investigate the structural properties of periphyton mats, I collected mats from short sites in Taylor Slough to section and analyze under a light microscope. I cut

small portions of the mats $\left(\sim 1.5 \mathrm{~cm}^{2}\right)$ and dehydrated the tissue to later embed in paraffin. Paraffin-embedded mats were then cut using a microtome. The thickness of the sections was $\geq 30 \mu \mathrm{m}$, depending on how well the embedded tissue cut at the different thicknesses. I mounted cut sections on gelatin-subbed microscope slides that were later deparaffinized. I used a Leica DMLS microscope to observe the sections, and pictures were taken using a Nikon H-III photo system.

\section{Laboratory experiment}

In July 1998, I conducted a laboratory experiment to test for the effects of periphyton mat integrity on the ability of consumers to differentially consume algal taxa. I used plastic tanks ( $50 \mathrm{~cm}$ long $x 35 \mathrm{~cm}$ wide; $22 \mathrm{~cm}$ high) with $1300 \mathrm{ml}$ of water. The treatments were "intact mat" or "blended mat". Intact-mat treatments refer to those that received a periphyton mat that remained intact as collected from the field. The blendedmat treatments received a periphyton mat that was shaken up in a closed container to destroy mat structure. I collected all the mats from the same location (Shark Slough) and their size was standardized $\left(52.5 \mathrm{~cm}^{2}\right)$ before being assigned to a treatment. Treatments were randomly assigned to either shrimp or mosquitofish. 
The fish and shrimp had been starved for 3 days to minimize confounding effects due to previously ingested contents and to purge stomach contents. I randomly picked 3 specimens of each consumer and analyzed their guts under a dissecting scope to ensure that their stomachs had indeed been cleared. Once the mats (blended or intact) were added to the tanks, I added the grazers. I added 3 mosquitofish or 3 shrimp per tank, with 6 replicates per treatment per grazer type for a total of 24 tanks.

The experiment ran for 3 days after which I collected the grazers and sacrificed them using the anesthetic MS222. I preserved them with $10 \%$ formalin, then transferred them to $70 \%$ ethanol. Stomachs were dissected using a dissecting scope and contents were mounted on permanent slides using a phenol-based mounting medium (CMCP-10, Polysciences Inc., Warrington, PA). I enumerated the stomach contents using a Leica DMLS microscope (10X and 40X objectives). For algal taxa, contents were reported as numbers of biological units (i.e., cells for unicellular taxa, $10-\mu$ segments for filamentous taxa, colonies for colonial taxa, etc.), unless otherwise noted.

\section{Statistical analyses}

The data followed a normal distribution and residuals satisfied assumptions of homoscedasticity for the Preliminary and Wet season experiment. Therefore, I used untransformed data for my analyses. For the Dry season experiment, chlorophyll a and AFDM were log-transformed and TP was square root-transformed to satisfy normality assumptions. I did all analyses with SYSTAT 8.0 (SPSS, Inc. 1998). I report coefficients of determination (CD) for significant terms as a measure of effect size. The $\mathrm{CD}$ reports the percentage of total variance uniquely attributable to each factor, and 
because of multicolinearity, the sum of the CDs might not add to the model $R^{2}$ (Trexler 1997).

Results from the Preliminary experiment made obvious the inclusion of a control for "complex" top-down (stimulatory) consumer effects on periphyton, so I included grazer-exclusion bags in successive field experiments (Wet and Dry season experiments).

Because I was concerned that there were some methodological artifacts in bags that would result in unwanted differences between cages and bags, I performed a t-test for the means of the control treatments ( 0 densities of both consumers) for cages and bags to determine if these means were significantly different.

For consumptive effects, I analyzed the data of cages and bags combined, including a "compartment" (cage or bag) factor. In these analyses, the emphasis was on the compartment factor to determine if mean periphyton biomass for bags was different from cage mean periphyton biomass. Additional information on the effect of increasing consumer density on consumption or on "complex" top-down effects was revealed by analyzing cages and bags separately and by looking at trends derived from these analyses.

I tested consumer effects on periphyton wet weight, AFDM, chlorophyll a, and TP. All dependent variables (except for TP for the Wet season experiment) were calculated as proportion increase or decrease from the initial values of biomass to normalize for initial variability, and to allow for comparisons between compartments (cage and bags). Negative values represent proportion decrease from initial values whereas positive values represent proportion increase from initial values.

Growth rate of consumers was calculated as the difference between the final average length and the initial average length per cage, divided by the duration of the 
experiment in days. The values reported are grand averages (across cages). I analyzed density-dependent effects on consumer log-transformed growth with ANOVA. For consumer growth during the Wet season experiment, I combined short and long hydroperiod, but I also report the effect of hydroperiod on growth. I report survival as the average percentage survival per site, which is the average of survival per cage.

Effects that may result from spatial patchiness in the field were removed by introducing a block factor in the statistical analysis for some of my experiments. For the Preliminary experiment, data were analyzed with ANOVA as a blocked, $3 \times 3$ full factorial design. For the Wet season experiment, no blocking was necessary. To test for hydroperiod effects in the Wet season experiment, I analyzed the differences of the short hydroperiod and long hydroperiod means as the dependent variables for the ANOVA. I also conducted separate analyses for long and short hydroperiod sites using ANOVA in a $3 \times 3$ full factorial design. For the Dry season experiment, I also used a block factor and analyzed the data as a blocked, $3 \times 3$ full factorial ANOVA.

Effect size is defined as the difference between means of an experimental treatment and a control treatment, and can be standardized by dividing this difference by the pooled within-treatment standard deviation (Richardson 1996, Osenberg et al. 1997). Although standardization of effect size is useful for meta-analyses, a simpler index of effect size is just the difference between the experimental and control means. This latter index of effect size has the advantage of being expressed in the original units of measurement (Richardson 1996), and is the one that I used in subsequent analyses. According to Osenberg et al. (1996), when calculating power the important aspect of effect size is the "absolute size of the change and not the sign." Because the dependent 
variables in this study are expressed as proportion increase or decrease from an original value, both positive and negative values are likely to occur. Therefore, I used the absolute value of the difference as a measure of effect size (i.e., e.s. $=\left|\mu_{t}-\mu_{c}\right|$, where $\mu_{t}$ represents the mean of the experimental treatment and $\mu_{\mathrm{c}}$ the mean of the control treatment). In order to compare the effect sizes observed in my experiments with typical effect sizes reported in the literature for grazer-periphyton interactions, I performed $a$ posteriori power analyses (Appendix) for the three field experiments using the observed effect sizes in my experiments. I also repeated power analyses for the three field experiments using a hypothetical effect size of $1 / 2$ the control mean (i.e., treatment means are $1.5 \mathrm{x}$ the control means), effect size that Feminella and Hawkins (1995) considered to be biologically significant in their review of 89 studies of periphyton-grazer interactions.

For the laboratory experiment, algal taxa were pooled in 4 broad categories: filamentous blue-greens, coccoid blue-greens, green algae and diatoms, and I also included a fifth category that lumped all invertebrates (dinoflagellates, cilliates, rotifers, ostracods, copepods, chydorids, cladocerans, mites, insects, trichopterans, chironomids, and nematodes). I transformed the data using the square-root transformation to fulfill normality assumptions. I analyzed the data separately for fish and shrimp using MANOVA, and univariate ANOVAs to report separate $P$ values for individual dependent variables. In the analysis for shrimp, the diatom category was removed because there was no variation in the dependent variable (i.e., all replicates had a value equal to zero). 


\section{Results}

\section{Preliminary experiment}

Fish and shrimp increased periphyton biomass in cages consistently for all biomass measures (wet weight, chlorophyll a, and AFDM proportions) (Fig. 3). The presence of shrimp significantly increased periphyton wet weight proportion and chlorophyll a proportion, explaining approximately $30 \%$ of the total variation in both dependent variables (Table 5). Although not significant, AFDM proportion means were higher at higher densities of shrimp. Periphyton wet weight, AFDM, and chlorophyll a proportions increased with increasing fish density (Fig. 3), but only the effects for periphyton wet weight proportion were significant (Table 5). Blocks were significant for periphyton wet weight proportion and marginally significant for chlorophyll a and AFDM proportions (Table 5).

Grass shrimp and mosquitofish appeared to thrive in the cages during the experiment because they grew and had high survivorship. Average shrimp growth for combined short and long hydroperiods over the length of the experiment was 0.015 $\mathrm{mm} /$ day, and $0.086 \mathrm{~mm} /$ day for mosquitofish growth. Both consumers exhibited negative density-dependent effects on their growth, growing less at higher consumer densities. Shrimp density was a significant factor decreasing shrimp growth explaining approximately $55 \%$ of the variance $\left(F_{1,10}=18.688, P=0.002\right.$, Model $\left.R^{2}=0.708, \mathrm{CD}=0.55\right)$. For mosquitofish, fish density $\left(F_{1,10}=6.446, P=0.029\right.$, Model $\left.R^{2}=0.749, \mathrm{CD}=0.16\right)$, shrimp density $\left(F_{2,10}=4.072, P=0.051, \mathrm{CD}=0.21\right)$, and the interaction of fish density $\mathrm{x}$ shrimp density $\left(F_{2.10}=5.186, P=0.029, \mathrm{CD}=0.26\right)$ all negatively affected their growth rate. 


\section{Wet season experiment}

Control (no consumers present) treatment means for all periphyton biomass measures for cages and bags were not significantly different from each other as revealed by t-tests for short and long hydroperiod sites (Table 6). Thus, in the following results I interpret all differences between cages and bags within cages ("compartment" effects) as a result of consumer treatments.

In testing for hydroperiod effects, the compartment (cage or bag) factor for the combined analysis of cages and bags was non-significant. Neither were consumer density effects on periphyton biomass in cages and bags separately. Nevertheless, I believe biological differences in the type of periphyton mats characteristic of each hydroperiod are important. Thus, despite no significant hydroperiod effects, further analyses were conducted separately for long and short hydroperiod sites.

Consumptive effects were noted for fish and shrimp for periphyton wet weight, chlorophyll a, and AFDM proportion in both long and short hydroperiod. For all variables, mean periphyton proportion change in biomass for cages was consistently below mean periphyton proportion change for bags (Table 7). The compartment factor (cage vs. bag) was significant in both short and long hydroperiod for periphyton wet weight proportion $\left(F_{1,30}=8.398, P=0.007\right.$, Model $R^{2}=0.400, \mathrm{CD}=0.17$ for short hydroperiod sites, and $F_{1,36}=19.323, P=0.000$, Model $R^{2}=0.471, \mathrm{CD}=0.28$ for long hydroperiod sites $)$, and AFDM proportion $\left(F_{1,30}=17.203, P=0.000\right.$, Model $R^{2}=0.581$, $\mathrm{CD}=0.24$ for short hydroperiod sites; and $F_{1,36}=18.729, P=0.000$, Model $R^{2}=0.518$, $\mathrm{CD}=0.25$ for long hydroperiod sites), but not for chlorophyll a proportion (Fig. 4). None of the interactions were significant for any of the hydroperiods. 
Separate analyses of cages and bags indicated that consumers had variable effects on periphyton biomass. For shrimp, effects on periphyton biomass were different for long and short hydroperiod (Fig. 5). For fish, means for all dependent variables were similar and showed decreasing or constant trajectories with increasing fish density for both short and long hydroperiod sites (Fig. 6).

Periphyton wet weight proportion increased with increasing shrimp density in cages of the long hydroperiod site (Table 8A), while AFDM proportion increased with increasing shrimp density in cages of the short hydroperiod site (Table 8B), but significantly decreased in bags of short hydroperiod sites (Table 8C). The interaction of shrimp and fish was also significant for periphyton wet weight proportion in long hydroperiod sites (Table 8A). Fish decreased AFDM proportion in bags in the long hydroperiod site although this result was only marginally significant (Table 8D). Increasing consumer density (shrimp or fish) did not have a significant effect on periphyton TP (Fig. 5 and 6) in any of the hydroperiods.

In this experiment, consumers grew albeit less than for the Preliminary experiment. Over the length of this experiment, shrimp grew $0.011 \mathrm{~mm} /$ day on average, whereas mosquitofish grew $0.074 \mathrm{~mm} /$ day for both hydroperiods combined. Nevertheless, shrimp grew significantly more in short hydroperiod sites than in long hydroperiod sites $\left(F_{1,27}=5.335, P=0.029\right.$, Model $\left.R^{2}=0.387, \mathrm{CD}=0.12\right)$, although there were no significant hydroperiod effects on mosquitofish growth. For both hydroperiods combined, shrimp exhibited intraspecific density-dependent effects on their growth ( $F$ $1,34=4.689, P=0.039$, Model $R^{2}=0.266, \mathrm{CD}=0.12$ ), but this was not noted for fish. 
Consumers had lower survival than for the Preliminary experiment: survivorship for shrimp was poor in this experiment (46\%), but better for mosquitofish (80\%).

Dry season experiment

Control (no consumers present) treatment means for all periphyton biomass measures for cages and bags were not significantly different from each other as revealed by t-tests (Table 6 ). Thus, in the following results I interpret all differences between cages and bags within cages ("compartment" effects) as a result of consumer treatments.

Consumers had a consumptive effect for periphyton wet weight, chlorophyll a, and AFDM proportions, as reflected in lower least square means for cages than for bags (Table 9). Overall, the compartment factor (cage or bag) was significant for periphyton wet weight proportion $\left(F_{1,89}=56.625, P=0.000\right.$, Model $\left.R^{2}=0.519, \mathrm{CD}=0.31\right)$ and for AFDM proportion $\left(F_{1,89}=9.553, P=0.003\right.$, Model $\left.R^{2}=0.203, \mathrm{CD}=0.08\right)$, but not for chlorophyll a or TP (Fig. 7).

Separate analyses for cages and bags indicated that the effects of fish and shrimp were different for this experiment as compared with trends for the Wet season experiment (Fig. 8). Increasing shrimp density significantly reduced periphyton wet weight proportion in cages $\left(F_{2,44}=3.964, P=0.026\right.$, Model $\left.R^{2}=0.271, \mathrm{CD}=0.13\right)$, and mosquitofish significantly increased periphyton wet weight in the bags $\left(F_{2,44}=7.389\right.$, $P=0.002$, Model $R^{2}=0.321, \mathrm{CD}=0.23$ ). Site (block) was significant only for cage periphyton wet weight proportion $\left(F_{1,44}=4.684, P=0.036\right.$, Model $\left.R^{2}=0.271, \mathrm{CD}=0.08\right)$, cage TP $\left(F_{1,44}=33.737, P=0.000\right.$, Model $\left.R^{2}=0.466, \mathrm{CD}=0.41\right)$, and bag $\operatorname{TP}\left(F_{1,43}=12.654\right.$, 
$P=0.001$, Model $R^{2}=0.249, \mathrm{CD}=0.22$ ). Increasing consumer density did not have a significant effect on chlorophyll a or TP.

For this experiment, I did not measure grazer growth rate, but grazer survival was comparable to the Preliminary experiment. Survival for shrimp was exactly as in the Preliminary experiment $(97 \%)$, but for mosquitofish it was $5 \%$ lower $(91 \%$ versus $96 \%$ in Preliminary experiment).

\section{Power analyses and effect size}

Power for the field experiments was consistently low $(<<0.80)$, but when analyses were repeated assuming a hypothetical effect size of $1 / 2$ the control mean and keeping variability and sample size constant, power increased substantially for all field experiments (Fig. 9, 10, and 11). Observed effect sizes were much smaller than those reported in the literature as biologically significant, consistently affecting the low magnitude of power.

\section{Cross sections of periphyton mats}

Microscopic observation of cross sections of paraffin-embedded periphyton mats revealed that periphyton mats have a high content of $\mathrm{CaCO}_{3} \cdot \mathrm{CaCO}_{3}$ gets deposited on the sheath of the blue-green filaments, surrounding them and increasing the filament diameter almost twice its size (Plate 1). It is also evident that these calcified filaments interweave to form a well-structured matrix (Plate 2).

In cross section, the periphyton mats present a distinct orientation that gives the mat polarity (i.e., recognizable top and bottom layers) (Plate 2). The top of the mat is 
aggregated loosely, and there are some calcified filaments as well as non-calcified ones (Plate 2A). Sometimes $U$. cornuta is visible inside the periphyton mats (Plate 1). Although Utricularia species are generally found near the top layers of the mat, I have observed Utricularia filaments almost half way through the mat. This indicates that light penetration through the mat might be sufficient for photosynthesis well below the surface of the mat. The middle section of the mat is mainly formed by blue-green filaments with heavy $\mathrm{CaCO}_{3}$ encrustation (Plate 2B). The heavy encrustation makes this portion of the mat more cohesive and aggregated than the top portion. The bottom of the mat is composed of older filaments, of which only the $\mathrm{CaCO}_{3}$ or remnants of their sheaths remain (Plate 2C). Sometimes, old and dead macrophyte stems are visible near the bottom layers of the mat; these stems might provide a substrate for mat formation. Green algae (Plate 3), and some invertebrates (Plate 4, and 5) also dwell in the mat. Interestingly, there seem to be diatom "pockets" inside the mat, where groups of diatoms form aggregates (Plate 6).

\section{Laboratory experiment}

Treatment (blended mat vs. intact mat) affected the ability of mosquitofish to differentially consume different prey items present in the periphyton mats, but this result was not observed for shrimp. The integrity of the mat was a significant factor affecting mosquitofish consumption of all categories of prey (Wilk's Lambda=0.131, Fstatistic $=7.950, P=0.013$ ), but had no effect on shrimp (Wilk's Lambda=0.685, Fstatistic $=0.804, P=0.560)$. 
For mosquitofish in particular, univariate F-tests revealed that treatment (blended vs. intact periphyton mats) affected the ability of mosquitofish to differentially consume more edible algal taxa. Means for numbers of diatoms and green algae found in mosquitofish gut contents were higher in the blended mat treatments than in the intact mat treatment. For the blended mat treatment, the mean numbers of diatoms and green algae per gut were 3.293 and 6.603 respectively. For the intact mat treatments, mean number of diatoms was 1.299, whereas mean number of green algae was 2.245. Mosquitofish ingested significantly more diatoms $\left(F_{1,10}=28.645, P=0.000\right)$ and green algae $\left(F_{1,10}=33.223, P=0.000\right)$ in the blended mat treatments than in the intact mat treatments.

Although not significant, coccoid blue-greens also showed increased occurrence in mosquitofish guts from blended mat treatments than from intact mat treatments. Invertebrates in mosquitofish guts showed an opposite trend: the number of invertebrates was higher in mosquitofish guts from intact mats than from blended mats, but this result was not significant. For shrimp, only green algae were substantially higher in the blended mat treatments than in the intact mat treatments, but this result was not statistically significant.

\section{Discussion}

\section{Consumer effects on periphyton}

Collectively, my experiments reveal the complex nature of consumer-periphyton interactions. The results of the field experiments indicate consumers had consumptive effects on periphyton, but in several instances these processes were coupled with and 
sometimes compensated by "complex" top-down effects, yielding enhancement of periphyton biomass. Compensation of consumer effects in aquatic systems has been suggested by other researchers (e.g., Porter (1976), Sterner (1986, 1990), McCormick (1994), and Kupferberg (1997)), although the paucity of studies that address these effects in aquatic systems is obvious when compared with terrestrial systems.

Because in almost all instances mean periphyton biomass change in bags was greater than periphyton biomass change in cage, I discarded scenario \#1 (Fig. 1), and concluded that consumption was an important process affecting periphyton biomass. But I predicted that consumption only--without physical stimulation and/or nutrient regeneration effects-- would show trends in cages and bags as in scenario \#2 (Fig. 1). In particular, bag means should have stayed constant with increasing grazer density, whereas cage means should have decreased with increasing grazer density; this pattern was never observed. Therefore I conclude that compensatory consumer effects concealed pure consumptive effects. In other words, consumption per se was never an isolated process affecting periphyton biomass. Hypothetical trends for physical stimulation were depicted in scenario \#5 (Fig. 1). Because I never observed these trends in any of my field experiments, I conclude that all compensatory effects of consumers were brought about by nutrient regeneration (scenarios \# 3 and \#4) and trophic cascades (scenario \#6) (Fig. 1).

The interaction between consumption and nutrient regeneration varied among experiments and consumer types. For example, I assumed that any parallel trajectory of means with increasing grazer density between bag and cage would be indicative of weak consumption (relative to nutrient regeneration) coupled with nutrient regeneration 
processes only if periphyton biomass was enhanced simultaneously in cage and bag (scenario \#3) (Fig. 1). This was the case for shrimp in long hydroperiod sites of the Wet season experiment. The increase of periphyton biomass means with increased shrimp density suggested shrimp enhancement of periphyton growth by nutrient regeneration. Because the consumers of this study are omnivores, they can mobilize nutrients locked up in other prey items and provide an allochthonous subsidy for periphyton, compensating for less-than-perfect efficiency in nutrient recycling by consumers (Vanni 1996). Other research teams found evidence for nutrient regeneration, although they worked with phytoplankton-based systems and with other consumers (Vanni and Findlay 1990, Matveev et al. 1994, Vanni and Layne 1997).

At times, consumptive effects were strong relative to nutrient regeneration, as indicated by trends similar to those depicted in scenario \#4 (Fig. 1). I detected this pattern for fish in the Dry season experiment (Fig. 8), but not for fish in the Wet season experiment (Fig. 6). I believe the difference lies in the higher fish density for the Dry season experiment, changed to better reflect natural densities for that site. Higher density increased the power to detect a treatment effect (Feminella and Hawkins 1995). Trends for shrimp in the Dry season experiment were not as well delineated as for the fish, but could also be categorized as fitting scenario \#4 (means in bags increased, whereas means in cages decreased) (Fig. 1).

There was also evidence of cascading trophic effects in one case. I hypothesized that trophic cascading effects would be indicated by a trajectory of bag means opposite (decreasing) to the trajectory of the cage means (increasing) (scenario \#6) (Fig. 1). This was the case for shrimp in short hydroperiod sites of the Wet season experiment, where 
periphyton AFDM declined in bags and increased in cages. This could result from the consumption of a true herbivorous species (probably invertebrates, such as amphipods or snails) by shrimp in cages, which releases periphyton from herbivory. Periphyton mats in short hydroperiod sites are more structured and thicker than those in long hydroperiod sites and may make them a better refuge for small herbivorous invertebrates than those in long hydroperiod sites. In long hydroperiod sites, nutrient regeneration by grazers may therefore swamp the effect of fewer herbivorous invertebrates eating periphyton. Nevertheless, the density of macroinvertebrates is generally lower in short hydroperiod sites than in long hydroperiod sites (Loftus et al. 1990, Pechmann et al. (in review)). Pechmann et al. (in review) concluded that the reason for this trend was because the "numbers [of organisms] are reduced by emigration, metamorphosis, mortality, and lack of oviposition when a site dries." Nevertheless, their results comprise macroinvertebrates that are sampled using a throw trap without quantifying organisms present inside periphyton mats. I would argue that if microinvertebrates were quantified by handpicking from inside the periphyton mats, there is a possibility that the observed trend would reverse. Therefore there could be more invertebrates in short hydroperiod mats than in long hydroperiod mats because of the greater structure and higher volume of periphyton mats in short hydroperiod sites, but this hypothesis needs to be tested. Besides, mats in short hydroperiod sites have a higher percentage of blue-green taxa than long hydroperiod sites, and therefore it is likely that the consumers, given the choice, would have picked more nutritional prey items (invertebrates over blue-green algae). This hypothesis could be supported by the fact that shrimp grew more in short hydroperiod sites than in long hydroperiod sites. 
Fish for the Wet season experiment were unusual in their trends. For fish in the Wet season experiment, both cage and bag trajectories of means for all periphyton biomass measures were almost parallel but seemed to slightly decrease with increasing mosquitofish density. The only significant decrease occurred in bags for periphyton AFDM. Cattaneo and Mousseau (1995) concluded that crowding of consumers led to a significant decrease in removal rates of periphyton. This could be a possible explanation for the trends in the cages only. But because both the bag and cage trajectories are almost parallel and decreasing, the same processes should be operating in both the cages and the bags, and so the density-dependent interference hypothesis proposed by Cattaneo and Mousseau (1995) seems unlikely.

Total phosphorous in the algal mats of the Wet and Dry season experiment was not significantly different over all consumer densities. I had predicted that TP should decrease if consumers had pure consumptive effects and reduced periphyton biomass but it should decrease less dramatically if nutrient regeneration by grazers was in operation. No biological process is $100 \%$ efficient; therefore, even if nutrient regeneration was important, not all the phosphorus consumed could be regenerated back to the periphyton, and so mean TP should slightly decrease in cages and bags. But observed means of TP in the Wet and Dry season experiment do not decrease with increasing consumer density, so this suggests that there could be an allochthonous input of phosphorus that compensates for the decrease in TP due to less-than-perfect efficiency of regeneration by the consumers (Vanni 1996). Because periphyton is severely phosphorus limited (Swift and Nicholas 1987, Flora et al. 1988, Vymazal et al. 1994, McCormick and O'Dell 1996, 
McCormick et al. 1996), even small nutrient inputs should be immediately captured by periphyton and incorporated into new biomass.

Consumers grew inside the experimental cages, but mosquitofish grew less than in other field cage studies $(0.12-0.24 \mathrm{~mm} /$ day, B. Loftus, unpublished data). 'This difference might be a result of seasonal differences because experiments were conducted at different times of the year. Consumer growth was depressed at high-density treatments, suggesting negative density-dependent effects. Gresens (1995) also noted that growth of snails was significantly lower at high densities. Consumer survival was high for the Preliminary and Dry season experiment, but low for the Wet season experiment. At the time of the Wet season experiment and due to an unexpected thunderstorm the day the grazers were supposed to be released in their cages, grazers had to stay overnight in plastic bags after they had been measured and separated by treatments. I believe they were exposed to oxygen stress and crowding, probably causing such high mortality. Although I counted the grazers that were alive and dead before introducing them in the cages and the next day I replaced the dead ones, there is no guarantee that the ones that were alive were in good condition. On the contrary, I believe they were already very stressed and died soon after I released them inside the cages.

Results from the Preliminary experiment underscore the importance of grazerexclusion bags in uncoupling consumer effects. Increasing fish and shrimp density can increase periphyton biomass (Fig. 3), but the process responsible for such a pattern is impossible to discern without the use of some type of control for physical stimulation or nutrient regeneration (the two likely processes to produce such on outcome). Because tests for bag artifacts determined that means for bags and cages were comparable, I 
conclude that the use of the grazer-exclusion bags successfully allowed me to separate and quantify consumptive effects from physical stimulation or nutrient regeneration on periphyton biomass of the Florida Everglades.

In summary, periphyton-animal interactions are variable and complex. The expression of this complexity was enhanced by the spatial and temporal variability among experiments of this study. According to the trends of my experiments, consumer processes operating on periphyton biomass were consumptive effects coupled to and compensated by "complex" top-down effects (enhancement of periphyton biomass through animal-regenerated nutrients or trophic cascades) but net consumptive effects were detected in only once out of 24 comparisons. Grazer-exclusion bags proved to be a simple tool to uncouple consumer effects, while the processes that more closely match biological reality were in operation inside cages.

\section{Effect sizes and interpretation of field experiments}

Interpreting field experimental results from studies of aquatic consumers is often challenging because of low statistical power (Polis 1994, Feminella and Hawkins 1995). For example, I believe several trends observed in my experiments were biologically important although not significant at the $\alpha=0.05$ level. Vanni and Layne (1997) raised their significance level to 0.1 because phytoplankton dynamics were variable in their study and they had limited replication. They emphasized that the goal of the study was to compare the magnitude of effects among different treatments and they concentrated on reporting these magnitudes "over detection of statistical differences from zero effect." Feminella and Hawkins (1995) conducted a meta-analysis that included results of 89 
studies on stream grazer-periphyton interactions and concluded that given the replication and the type I error $(\alpha)$ used in most studies, power to detect real differences in individual studies was extremely low, and studies suffered from high type II ( $\beta$ ) error. This point was also brought up by Polis (1994), who emphasized the limitations of experimental tests to assess the effect of omnivory on community dynamics. Results from power analyses for my experiments suggest that power was low because of small observed effect sizes (compared to what other authors consider biologically significant for other systems), and that power was adequate to detect the type of significant consumptive effects that are reported in the literature (e.g., Feminella and Hawkins 1995). Feminella and Hawkins (1995) considered an effect size biologically important if the treatment means were $1.5 \mathrm{x}$ the control means, and they concluded that their choice of the $1.5 \mathrm{x}$ factor was in the range of values reported in other meta-analysis studies in ecology. The issue remains then, how big an effect size is necessary for periphyton-consumer interaction to be an ecologically important process in the Florida Everlgades? Regardless of what cut-off point a researcher chooses, it is still an arbitrary metric, but it should be chosen so that it reflects the biology of the system or relationship in question. For the Everglades, I chose to work with mosquitofish and shrimp because dietary studies had concluded that they ingested periphyton and because of their high abundance in the system, therefore making them good candidates for regulation of periphyton biomass. I believe derivation of models that account for consumer-periphyton interactions are needed to determine if even the low effect sizes observed for this study when compared to typical effect sizes reported in the literature could be important for the regulation of the periphyton community. 
Polis and Strong (1996) argued that if an organism tends to feed on more than one class of food item, it should be categorized as an omnivore. Accordingly, omnivory is pervasive in ecology, and a researcher could conclude omnivory just by looking at stomach contents and classifying its contents as more than one category. From an ecological view, this definition might not be meaningful because it fails to consider the consumer's effect on the population dynamics of its prey (e.g., Power 1992, Osenberg and Mittelbach 1996). I would argue that an experimental approach to omnivory is necessary, where the effect of the consumer on the resource needs to be classified as "functional" (consumer has a regulatory effect on the resource) or "non-functional" (consumer has no regulatory effect on the resource). Only then can the term "omnivore" have some ecological meaning that links an observation (presence-absence of a particular prey item in the guts of a predator) with an ecological relationship between consumer and resource. Polis (1994) argues that "without experimentation, one cannot a priori decide which are strong or weak links," or that "dynamics cannot be predicted from data on diet or energy flow," but no distinction has been made yet between observation of omnivory and rigorous experimentation on omnivory. He contends that at best, observational data might suggest initial clues to assess importance of links and might add or complement conclusions after experiments have been conducted. In the Everglades, mosquitofish and shrimp could be categorized as "functional" omnivores because they have significant consumptive effects on periphyton biomass, although coupled and sometimes compensated by "complex" top-down effects. The importance of assessing "complex" top-down effects when testing for consumer-resource interactions is underscored by this 
study, where only after experimentation it became apparent that "complex" top-down effects could mask consumptive effects.

Consumer-periphyton dynamics in the Everglades: an edibility issue?

The net effect of consumption of periphyton in these experiments was coupled and sometimes compensated by processes that stimulated periphyton biomass. This suggests the hypothesis that periphyton will accrue in great quantities assuming no other consumer has functionally important consumptive effects either. The structure and characteristics of the periphyton mats, as well as the particular suite of species forming the mats, may be partly responsible for the lack of significant, pure consumptive effects by the consumers of this study. The periphyton community in the Everglades is primarily made up of different taxa of algae (diatoms, blue-green algae, and green algae) that form a matrix harboring invertebrates, fungi, bacteria, detritus, and macrophytes. The mat seems to hold together as a result of a well-structured matrix of filaments (Gleason and Spackman 1974, pers. obs.). Usually, the matrix is formed by $\mathrm{CaCO}_{3}$-encrusting bluegreen algae, but also filamentous macrophytes as $U$. gibba and/or $U$. cornuta (Plate 1, J. Richards, pers. comm.), and floating macrophytes such as $U$. purpurea (purple bladderwort) (Ulanowicz 1995, pers. obs.). It has been suggested that the Utriculariaperiphyton component be considered as a functional assemblage with cohesive unity and a "self-organizing ecosystem aggregate" (Bosserman 1979); efforts have been made to separate the periphytic component from the macrophytes, but they have not been completely successful (Ulanowicz 1995, pers. obs.). Also, periphyton in the Everglades 
is strongly phosphorus limited (Swift and Nicholas 1987, Flora et al. 1988, Vymazal et al. 1994, McCormick and O'Dell 1996, McCormick et al. 1996).

Microscopic observations of cross sections of paraffin-embedded periphyton mats revealed a pattern that could potentially hide the edible live cells inside the mat (Plates 3 and 6). Moreover, periphyton mats can be very thick in the Everglades (up to 5-cm thick) (pers. obs.). In this manner, grazers would not have direct access to some parts of the mats where the edible material lies. $\mathrm{CaCO}_{3}$ crystals are very abundant in the sheaths of many blue-green filaments, which could be linked to their inedibility (Plate 1). Merz (1992) argued that $\mathrm{CaCO}_{3}$ encrustation could benefit the filaments by shading the algae from extreme irradiance, thus protecting the filaments from damaging radiation, or serving as ion sinks in the process of $\mathrm{OH}$ removal after bicarbonate ions are used for photosynthesis. Several other studies suggested that $\mathrm{CaCO}_{3}$ could also act as grazer deterrent, at least for marine systems (Pennings and Paul 1992, Hay et al. 1994). I suggest the role of $\mathrm{CaCO}_{3}$ as consumer deterrent for freshwater systems too, but further studies are needed to corroborate this hypothesis.

The laboratory experiment demonstrated that the structure of the periphyton mat proved to be critical for the consumers that feed on it. Nicotri (1977) suggested that selective removal of diatoms by snails in his experiment was facilitated in part by the location of these algal taxa in the outermost areas of the algal mat. Specifically for mosquitofish, the integrity of the mat hindered the access to more palatable or edible species that accumulated inside the mat. Green algae and diatoms are believed to be more palatable algal taxa than blue-green algae (Porter 1977, Lamberti 1996) and these were the two algal taxa for which periphyton mat treatment (blended vs. intact) had a 
significant effect on their presence in mosquitofish stomachs. Nevertheless, visual comparison of mosquitofish gut contents from the field and from my laboratory experiment suggest that mosquitofish might prefer invertebrates to periphyton because field mosquitofish guts are filled with invertebrates and have little periphyton (pers. obs.). Bowen et al. (1995) noted that invertebrates are food of better quality in terms of protein and energy than primary producers such as macrophytes, algae, and detritus are. The presence of periphyton in the gut contents of mosquitofish in the laboratory experiment might be explained by the fact that the only food available to them was a piece of periphyton mat with no other source of invertebrates.

Because the periphyton mats in the Everglades are primarily composed of bluegreen filamentous taxa, palatability and nutritional value are other important aspects to consider. Browder et al. (1982) suggested that diatom-based periphyton from the Everglades was the most nutritious ration for tadpoles, followed by green algae. They also concluded that no growth occurred in tadpoles fed on a blue-green-based periphyton. Braslau (1998) found opposite results, with blue-greens being the ration that elicited the highest growth on tadpoles, although she worked with a different species of blue-green alga (Chroococcus) and in a different system. Kupferberg et al. (1994) concluded that tadpoles of Pacific treefrogs grew most rapidly with a diet of filamentous greens with epiphytes, and apparently the epiphytes growing on these filaments could dramatically affect growth and time to metamorphosis. Tadpoles fed Nostoc (a colonial blue-green) grew poorly compared to other algal diets, probably as a result of structure, toxicity, or low nutritional value. The nitrogen value of blue-greens approaches that of some animals, such as microcrustaceans, because of nitrogen fixation in many species, but the 
toxicity and palatability might inhibit herbivory (Lamberti 1996). Schmidt and Jónasdóttir (1997) found that even if blue-green algae were a poor food when fed alone to copepods, they proved to be a good supplement in the diet. Several studies suggest that there are many factors, such as toxicity, lipid content (e.g. polyunsaturated fatty acidsPUFA), protein content, and sugar composition, affecting the edibility and nutritional value of a particular alga (Arnold 1971, Brown 1991, Schmidt and Jónasdóttir 1997, Ahlgren et al. 1992).

Finally, ecological stoichiometric theory (Sterner 1990) suggests that the chemical composition (stoichiometry) of an organism and its prey, as manifested by its carbon, nitrogen, and phosphorus elemental values, will usually dictate the quantity and quality of these nutrients that the organism recycles. It follows that organisms will be enormously affected by the food quality of the prey they consume (Elser and Hassett 1994, Sterner and Hessen 1994). Specifically, nutrient-limited resources will impose a "stoichiometric food-quality constraint" on consumer growth and reproduction ("food quality hypothesis") (Elser et al. 1998). Several studies have now confirmed that growth and reproduction of Daphnia are depressed when they are fed low-quality food (P-limited algae), reflecting Daphnia's high P somatic requirements (Urabe and Watanabe 1992, Sterner 1993, Sterner et al. 1993, MacKay and Elser 1998). Therefore, organisms might benefit if they ingest prey items that closely match their stoichiometric demands. Periphyton carbon:nitrogen:phosphorus (TC:TN:TP) ratios in the Everglades center around 6985:280:1. For example, for phosphorus (the limiting nutrient in this system), periphyton TP molar concentration is approximately $2.72 \times 10^{-6}$, and mosquitofish TP is approximately $1.1 \times 10^{-3}$. As evidenced by these values, periphyton does not seem to be a 
suitable food item given the animals' TP demands. Jones et al. (1997) suggested that high $\mathrm{C}: \mathrm{N}$ ratios (>17:1) could be deleterious for consumers because they influence palatability, and for Everglades periphyton the $\mathrm{C}: \mathrm{N}$ ratio is approximately $25: 1$. Nevertheless, experiments are needed to determine if, given other choices, consumers will prefer prey with stoichiometric values that more closely match their own.

In summary, calcium carbonate encrustation by several of the algal taxa, hidden algal cells inside the mat, high abundance of thick-sheathed blue-green algae, low TP ratios, and their thickness are unique features of periphyton mats in the Everglades. All these properties of Everglades periphyton could contribute to inedibility and they could act as consumer deterrents, lessening the consumptive effects from consumers, or allowing for periphyton biomass to accrue without being consumed. Along with the lack of net consumption as a result of stimulatory or compensatory effects by consumers, these characteristics could potentially explain the high biomass of periphyton in this system.

\section{Conclusion}

Shrimp and mosquitofish are omnivores that ingest periphyton although net consumptive effects were rare in this study, and consumptive effects were coupled with and sometimes compensated by "complex" top-down effects. This study suggests that these omnivores significantly enhance periphyton biomass by various mechanisms such as by nutrient regeneration or by trophic cascades on strict herbivores ("functional" omnivores). Characteristics of periphyton mats of the Florida Everglades may hide the more edible algal taxa (green algae and diatoms) and lessen consumptive effects of 
consumers, leading to high periphyton biomass in the system. Detection of significance in processes that seem to be strong in delineating biomass patterns should be fairly easy, given high replication and enough power, but small effect sizes cause problems when it comes to detecting significance, particularly in field studies. Nevertheless, far from being issues of concern for researchers, small effect sizes might be real and could potentially reflect true ecological processes, as I demonstrated in the present study. 


\section{Literature cited}

Agrawal, A. A., C. Kobayashi, and J. S. Thaler. 1999. Influence of prey availability and induced host-plant resistance on omnivory by western flower thrips. Ecology 80: 518-523.

Ahlgren, G., I. B. Gustafsson, and M. Boberg. 1992. Fatty acid content and chemical composition of freshwater microalgae. Journal of Phycology 28: 37-50.

Arnold, D. E. 1971. Ingestion, assimilation, survival, and reproduction by Daphnia pulex fed seven species of blue-green algae. Limnology and Oceanography 16: 907-920.

Beck, J. T., and B. C. Cowell. 1976. Life history and ecology of the freshwater caridean shrimp, Palaemonetes paludosus (Gibbes). American Midland Naturalist 96: 5265 .

Belsky, J. A., W. P. Carson, C. L. Jensen, and G. A. Fox. 1993. Overcompensation by plants: herbivore optimization or red herring? Evolutionary Ecology 7: 109-121.

Bosserman, R.W. 1979. The hierarchical integrity of Utricularia-periphyton microecosystems. Ph.D. Dissertation, University of Georgia, Athens, GA.

Bowen, S. H., E. V. Lutz, and M. O. Ahlgren. 1995. Dietary protein and energy as determinants of food quality: trophic strategies compared. Ecology 76: 899-907.

Braslau, V. 1998. Algal composition influences on tadpole growth and metamorphosis in the green treefrog, Hyla cinerea. New York, Bard College. Master's Thesis.

Browder, J. A., A. Black, and D. Black. Undated. Comparison of laboratory growth of Hyla squirella tadpoles on Everglades periphyton of three taxonomic compositions. Unpublished report to Everglades National Park, Homestead, Fl. $12 \mathrm{pp}$.

Browder, J. A., D. Cotrell, M. Brown, M. Newman, R. Edwards, J. Yuska, M. Browder, and J. Krakoski. 1982. Biomass and primary production of microphytes and macrophytes in periphyton habitats of the southern Everglades. Report T-662, South Florida Research Center, Homestead, FL, 49 pp.

Browder, J. A., P. J. Gleason, and D. R. Swift. 1994 . Periphyton in the Everglades: spatial variation, environmental correlates, and ecological implications. Pages 379-418 in S. M. Davis, and J. C. Ogden, editors. Everglades: the ecosystem and its restoration. St. Lucie Press, Delray Beach, FL.

Brown, M. R. 1991. The amino-acid and sugar composition of 16 species of microalgae 
used in mariculture. Journal of Experimental Marine Biology and Ecology 145 : 79-99.

Cattaneo, A., and B. Mousseau. 1995. Empirical analysis of the removal rate of periphyton by grazers. Oecologia 103: 249-254.

Eaton, A. D., L. S. Clesceri, and A. E. Greenberg, editors. 1995. Standard methods for the examination of water and wastewater. American Public Health Association, New York.

Elser, J. J., T. H. Chrzanowski, R. W. Sterner, and K. H. Mills. 1998. Stoichiometric constraints on food-web dynamics: a whole-lake experiment on the Canadian Shield. Ecosystems 1: 120-136.

Elser, J. J., M. M. Elser, N. A. MacKay, and S. R. Carpenter. 1988. Zooplanktonmediated transitions between $\mathrm{N}$ - and P-limited algal growth. Limnology and Oceanography 33: 1-14.

Elser, J. J., and R. P. Hassett. 1994. A stoichiometric analysis of the zooplanktonphytoplankton interaction in marine and freshwater ecosystems. Nature 370: 211213.

Feminella, J. W., and C. P. Hawkins. 1995. Interactions between stream herbivores and periphyton: a quantitative analysis of past experiments. Journal of the North American Benthological Society 14: 465-509.

Fennema, R. J., C. J. Neidrauer, R. A. Johnson, T. K. MacVicar, and W. A. Perkins. 1994. A computer model to simulate natural Everglades hydrology. Pages 249289 in S. M. Davis and J. C. Ogden, editors. Everglades: The ecosystem and its restoration. St. Lucie Press, Boca Raton, Florida.

Flora, M. D., D. P. Walker, D. J. Scheidt, R. G. Rice, and D. H. Landers. 1988. The response of the Everglades marsh to increased nitrogen and phosphorus loading. Part I: Nutrient dosing, water chemistry, and periphyton productivity. Report to the Superintendent, Everglades National Park, Homestead, Florida.

Gleason, P. J., and W. Spackman. 1974. Calcareous periphyton and water chemistry in the Everglades. Pages 146-181 in P. J. Gleason, editor. Environments of South Florida: present and past. Memoir No. 2, Miami Geological Society, Coral Gables, FL.

Gresens, S. E. 1995. Grazer diversity, competition and the response of the periphyton community. Oikos 73: 336-346.

Gunderson, L. H. 1994. Vegetation of the Everglades: Determinants of community 
composition. Pages 323-340 in S. M. Davis and J. C. Ogden, editors.

Everglades: The ecosystem and its restoration. St. Lucie Press, Boca Raton, Florida.

Havens, K. E., L. A. Bull, G. L. Warren, T. L. Crisman, E. J. Phlips, and J. P. Smith. 1996. Food web structure in a subtropical lake ecosystem. Oikos 75: 20-32.

Hay, M. E., Q. E. Kappel, and W. Fenical. 1994. Synergisms in plant defenses against herbivores: Interactions of chemistry, calcification, and plant quality. Ecology 75: $1714-1726$.

Hunt, B. P. 1952. Food relationships between Florida spotted gar and other organisms in the Tamiami Canal, Dade County, Florida. Transactions of the American Fisheries Society 82: 13-33.

Hunt, B. P. 1961. A preliminary survey of the physico-chemical characteristics of Taylor Slough with estimates of primary productivity. Pamphlet \#43-H. Everglades National Park, Homestead, Florida.

Jones, J. I, B. Moss, and J. O. Young. 1997. Interactions between periphyton, nonmolluscan invertebrates, and fish in standing freshwaters. Pages 69-90 in E. Jeppesen, M. Søndergaard, M. Søndergaard, and K. Christoffersen. The structuring role of submerged macrophytes in lakes. Springer-Verlag, New York, New York.

Kupferberg, S. 1997. Facilitation of periphyton production by tadpole grazing: functional differences between species. Freshwater Biology 37: 427-439.

Kupferberg, S. J., J. C. Marks, and M. E. Power. 1994. Effects of variation in natural algal and detrital diets on larval anuran (Hyla regilla) life-history traits. Copeia 2: 446-457.

Lamberti. G. A. 1996. The role of periphyton in benthic food webs. Pages 533-564 in R. J. Stevenson, M. L. Bothwell, and R. L. Lowe, editors. Algal Ecology. Academic Press, San Diego, California.

Lehman, J. T., and D. Scavia. 1982. Microscale patchiness of nutrients in plankton communities. Science 216: 729-730.

Leibold, M. A. 1989. Resource edibility and the effects of predators and productivity on the outcome of trophic interactions. American Naturalist 134: 922-949.

Loftus, W. F., J. D. Champan, and R. Conrow. 1990. Hydroperiod effects on Everglades marsh food webs, with relation to marsh restoration efforts. Conference on Science in the National Parks. Proceedings. Volume 6. Fisheries and Coastal 
Wetlands Research. Fourth conference on research in the National Parks and equivalent reserves. July 13-18, 1986. Gary Larson and Michael Soukup, editors. Colorado State University, Fort Collins, Colorado.

MacKay, N. A., and J. J. Elser. 1998. Factors potentially preventing trophic cascades: food quality, invertebrate predation, and their interaction. Limnology and Oceanography 43: 339-347.

Mapstone, B. D. 1996. Scalable decision criteria for environmental impact assessment. Pages 67-80 in R. J. Schmitt and C. W. Osenberg, editors. Detecting ecological impacts. Concepts and applications in coastal habitats. Academic Press, New York, New York.

Matveev, V., L. Matveeva, and G. J. Jones. 1994. Phytoplankton stimulation by mosquitofish in the presence of large Daphnia. Verh. Internat. Verein. Limnol. 25: 2193-2197.

McCormick, P. V. 1994. Evaluating the multiple mechanisms underlying herbivorealgal interactions in streams. Hydrobiologia 291: 47-59.

McCormick, P. V., and M. B. O'Dell. 1996. Quantifying periphyton responses to phosphorus in the Florida Everglades: a synoptic-experimental approach. Journal of the North American Benthological Society 15: 450-468.

McCormick, P. V., P. S. Rawlik, K. Lurding, E. P. Smith, and F. H. Sklar. 1996. Periphyton-water relationships along a nutrient gradient in the northern Florida Everglades. Journal of the North American Benthological Society 15: 433-449.

McCormick, P. V., R. B. E. Shuford III, J. G. Backus, and W. C. Kennedy. 1998. Spatial and seasonal patterns of periphyton biomass and productivity in the northern Everglades, Florida, U.S.A. Hydrobiologia 362: 185-208.

McNaughton, S. J. 1979. Grazing as an optimization process: grass-ungulate relationships in the Serengeti. American Naturalist 113: 691-703.

----. 1983. Compensatory plant growth as a response to herbivory. Oikos 40: 329-336.

----. 1985. Ecology of a grazing ecosystem: the Serengeti. Ecological Monographs 55: 259-294.

----. 1986. On plants and herbivores. American Naturalist 128: 765-770.

Merz, M. U. E. 1992. The biology of carbonate precipitation by cyanobacteria. Facies 26: 81-102. 
Morin, P. J., and S. P. Lawler. 1996. Effects of food chain length and omnivory on population dynamics in experimental food webs. Pages 218-230 in G. A. Polis and K. O. Winemiller, editors. Food Webs: Integration of patterns and dynamics. Chapman and Hall, New York, New York.

Neter, J., W. Wasserman, and M.H. Kutner. 1990. Applied statistical models. Regression, Analysis of variance, and experimental designs. Irwin, Illinois.

Nicotri, M. E. 1977. Grazing effects of four marine intertidal herbivores on the microflora. Ecology 77: 1020-1032.

Osenberg, C. W., and G. G. Mittelbach. 1996. The relative importance of resource limitation and predator limitation in food chains. Pages 134-148 in G. A. Polis and K. O. Winemiller, editors. Food Webs: Integration of patterns and dynamics. Chapman and Hall, New York, New York.

Osenberg, C. W., O. Sarnelle, and S. D. Cooper. 1997. Effect size in ecological experiments: The application of biological models in meta-analysis. American Naturalist 150: 798-812.

Osenberg, C. W., R. J. Schmitt, S. J. Holbrook, K. E. Abu-Saba, and A. R. Flegal. 1996. Pages 83-108 in R. J. Schmitt and C. W. Osenberg, editors. Detecting ecological impacts. Concepts and applications in coastal habitats. Academic Press, New York, New York.

Otto, C. 1983. Adaptations to benthic freshwater herbivory. Pages 199-205 in R. G. Wetzel, editor. Periphyton in freshwater ecosystems. Dr. W. Junk Publishers, The Hague.

Owen, D. F. 1980. How plants may benefit from the animals that eat them. Oikos 35: 230-235.

Paige, K. N., and T. G. Whitham. 1987. Overcompensation in response to mammalian herbivory: the advantage of being eaten. American Naturalist 129: 407-416.

Pechmann, J. H. K., J. C. Trexler, and W. G. DeLoach. In review. Variation in invertebrate and amphibian communities along a nutrient and hydroperiod gradients in sloughs in Everglades National Park.

Pennings, S. C., and V. J. Paul. 1992. Effect of plant toughness, calcification, and chemistry on herbivory by Dolabella auricularia. Ecology 73: 1606-1619.

Polis, G. A. 1991. Complex trophic interactions in deserts: An empirical critique of food-web theory. American Naturalist 138: 123-155. 
----. 1994. Food webs, trophic cascades and community structure. Australian Journal of Ecology 19: 121-136.

Polis, G. A., and D. R. Strong. 1996. Food web complexity and community dynamics. American Naturalist 147: 813-846.

Porter, K. G. 1973. Selective grazing and differential digestion of algae by zooplankton. Nature 244: 179-180.

----- 1976. Enhancement of algal growth and productivity by grazing zooplankton. Science 192: 1332-1334.

----. 1977. The plant-animal interface in freshwater ecosystems. American Scientist 65: $159-170$.

Power, M. E. 1990. Resource enhancement by indirect effects of grazers: armored catfish, algae, and sediment. Ecology 71: 897-904.

----. 1991. Shifts in the effects of tuft-weaving midges on filamentous algae. American Midland Naturalist 125: 275-285.

----. 1992. Top-down and bottom-up forces in food webs: do plants have primacy? Ecology 73: 733-746.

Pringle, C. M., and G. A. Blake. 1994. Quantifying effects of atyid shrimp (Decapoda: Atyidae) on the depositional environment in a tropical stream: Use of electricity for experimental exclusion. Canadian Journal of Fisheries and Aquatic Sciences 51: $1443-1450$.

Pringle, C. M., G. A. Blake, A. P. Covich, K. M. Buzby, and A. Finley. 1993. Effects of omnivorous shrimp in a montane tropical stream: sediment removal, disturbance of sessile invertebrates and enhancement of understory algal biomass. Oecologia 93: $1-11$.

Rader, R. B. 1994. Macroinvertebrates of the northern Everglades: species composition and trophic structure. Florida Scientist 57: 22-33.

Rader, R. B., and C. J. Richardson. 1992. The effects of nutrient enrichment on algae and macroinvertebrates in the Everglades: a review. Wetlands 12: 121-135.

Richardson, J. T. E. 1996. Measures of effect size. Behavior Research Methods, Instruments, \& Computers 28: 12-22.

SAS Institute Inc. 1991. SAS Language: Reference. Version 6. First Edition. SAS Institute Inc., Cary, North Carolina. 
Schmidt, K., and S. H. Jónasdóttir. 1997. Nutritional quality of two cyanobacteria: How rich is 'poor' food? Marine Ecology Progress Series 151: 1-10.

SPSS, Inc. 1998. Systat version 8.0. Chicago, Illinois.

Steinman, A. D. 1996. Effects of grazers on freshwater benthic algae. Pages 341-373 in R. J. Stevenson, M. L. Bothwell, and R. L. Lowe, editors. Algal ecology. Academic Press, New York, New York.

Sterner, R. W. 1986. Herbivores' direct and indirect effects on algal populations. Science 231: 605-607.

----. 1990. The ratio of nitrogen and phosphorus resupplied by herbivores: zooplankton and the algal competitive arena. American Naturalist 136: 209-229.

----. 1993. Daphnia growth on varying quality of Scenedesmus: mineral limitation of zooplankton. Ecology 74: 2351-2360.

Sterner, R. W., D. D. Hagemeier, W. L. Smith, and R. F. Smith. 1993. Phytoplankton nutrient limitation and food quality for Daphnia. Limnology and Oceanography 38: $857-871$.

Sterner, R. W., and D. O. Hessen. 1994. Algal nutrient limitation and the nutrition of aquatic herbivores. Annual Review of Ecology and Systematics 25: 1-29.

Stober, J., D. Scheidt, R. Jones, K. Thornton, L. Gandy, D. Stevens, J. Trexler, and S. Rathbun. 1998. South Florida ecosystem assessment. Vol. II. Final technical report. Appendices. Phase I. Monitoring for adaptive management: Implications for ecosystem restoration. EPA-904-R-98-002. Environmental Protection Agency, Athens, Georgia.

Swift, D. R. 1981. Preliminary investigation of periphyton and water quality relationships in the Everglades Water Conservation Areas. Technical Publication 81-5, South Florida Water Management District, West Palm Beach, Florida, 83 $\mathrm{pp}$.

Swift, D. R., and R. B. Nicholas. 1987. Periphyton and water quality relationships in the Everglades Water Conservation Areas. Technical Publication 87-2, South Florida Water Management District, West Palm Beach, Florida, 44 pp.

Trexler, J. C. Resource availability and plasticity in offspring provisioning: embryo nourishment in sailfin mollies. Ecology 78: 1370-1381. 
Turner, A. M., J. C. Trexler, C. F. Jordan, S. J. Slack, P. Geddes, J. H. Chick, and W. F. Loftus. In press. Targeting ecosystem features for conservation: standing crops in the Florida Everglades. Conservation Biology.

Ulanowicz, R. E. 1995. Utricularia's secret: the advantage of positive feedback in oligotrophic environments. Ecological Modelling 79: 49-57.

Urabe, J. J., and Y. Watanabe. 1992. Possibility of $\mathrm{N}$ or P limitation for planktonic cladocerans: and experimental test. Limnology and Oceanography 37: 244-251.

Van Meter-Kasanof, N. 1973. Ecology of the microalgae of the Florida Everglades. Part I. Environment and some aspects of freshwater periphyton. Nova Hedwigia 24: 619-664.

Vaughn, C. C. 1986. The role of periphyton abundance and quality in the microdistribution of a stream grazer, Helicopsyche borealis (Trichoptera: Helicopsychidae). Freshwater Biology 16: 485-493.

Vanni, M. J. 1996. Nutrient transport and recycling by consumers in lake food webs: implications for algal communities. Pages 81-95 in G. A. Polis and K. O. Winemiller, editors. Food Webs: Integration of patterns and dynamics. Chapman and Hall, New York, New York.

Vanni, M. J., and D. L. Findlay. 1990. Trophic cascades and phytoplankton community structure. Ecology 71: 921-937.

Vanni, M. J., and C. D. Layne. 1997. Nutrient recycling and herbivory as mechanisms in the "top-down" effect of fish on algae in lakes. Ecology 78: 21-40.

Vanni, M. J., C. D. Layne, and S. E. Arnott. 1997. "Top-down" trophic interactions in lakes: effects of fish on nutrient dynamics. Ecology 78: 1-20.

Vymazal, J., C. B. Craft, and C. J. Richardson. 1994. Periphyton response to nitrogen and phosphorus additions in Florida Everglades. Algological Studies 73: 75-97.

Vymazal, J. and C. J. Richardson. 1995. Species composition, biomass, and nutrient content of periphyton in the Florida Everglades. Journal of Phycology 31: 343354. 


\section{Appendix}

Power analyses can be performed using the "probf" function on SAS for an F test given a type I error ( $\alpha$ level), numerator degrees of freedom, denominator degrees of freedom, and a non-centrality parameter (SAS Institute Inc.). The non-centrality parameter that I used is $\lambda$, and was calculated using the following formulae (Neter, Wasserman, and Kutner 1990).

For main effect A:

$$
\begin{aligned}
& \phi=\sqrt{n b \sum \alpha_{i}^{2} / a \sigma^{2}} \\
& \text { and } \phi=\sqrt{\lambda / a}, \text { therefore } \lambda=\phi^{2} a \\
& \lambda=n b \sum \alpha_{i}^{2} / \sigma^{2} \\
& \alpha_{i}=\mu_{i}-\mu_{i}
\end{aligned}
$$

where $n$ is the number of replicates, $b$ is the number of levels for factor $\mathrm{B}, a$ is the number of levels for factor $\mathrm{A}, \mu_{i}$ is the mean of factor $\mathrm{A}$ at level $i, \mu$. is the grand mean, and $\sigma^{2}$ is the error term used in the F-test for the ANOVA (MSE). The formulae are equivalent for factor B.

For interactions $\mathrm{A} \times \mathrm{B}$ :

$$
\phi=\sqrt{n \sum \sum(\alpha \beta)_{i j}^{2} /[(a-1)(b-1)+1] \sigma^{2}} \text { and } \phi=\sqrt{\lambda /[(a-1)(b-1)+1]},
$$

therefore, $\lambda=\phi^{2} n$

$$
\begin{aligned}
& \lambda=n \sum \sum(\alpha \beta)_{i j}^{2} / \sigma^{2} \\
& (\alpha \beta)_{i j}=\mu_{i j}-\mu_{. j}-\mu_{i .}+\mu .
\end{aligned}
$$


where $n$ is the number of replicates, $\mu_{i j}$ is the mean of the interaction at level $i$ of factor A and level $j$ of factor $\mathrm{B}, \mu_{. . j}$ is the mean of level $j$ of factor B over all levels of $\mathrm{A}, \mu_{i .}$ is the mean of level $i$ of factor A over all levels of $\mathrm{B}$, and $\mu_{\text {.. }}$ is the grand mean.

For power analyses using a hypothetical effect size $=0.5 \mathrm{x}$ control means, I arbitrarily assumed a linear relationship among levels of a factor (i.e., levels of consumer density). Therefore, for shrimp $=20$, the effect size was the mean for shrimp $=0$ multiplied by 1.5 , and for shrimp $=20$ it was the mean for shrimp $=20$ multiplied by 1.5 . For the interactions, effect sizes for all combinations of 0 shrimp (regardless of fish density) were obtained by multiplying the control ( 0 shrimp, 0 fish) by 1.5 . Effect sizes for all combinations of shrimp $=20$ (regardless of fish density) were obtained by multiplying effect sizes for shrimp $=0$ by 1.5 . Effect sizes for all combinations of shrimp=60 (regardless of fish density) were obtained by multiplying effect sizes for shrimp=20 by 1.5. 
Table 1. Mosquitofish diet as revealed by analysis of stomach contents. Samples were taken from throughout the Everglades ecosystem; total number of fish analyzed=1270.

A) Percent of mosquitofish that ingested each food item

Food item Percentage of fish containing the food item

Periphyton $48.90 \%$

Dipteran adults $44.48 \%$

Chironomid larvae $9.92 \%$

Other* $9.76 \%$

Mites $8.58 \%$

Cladocerans $3.46 \%$

*Insects, spiders, fish, snails.

B) Average percent composition (by weight) of gut contents of mosquitofish

Food item

Periphyton

Dipteran adults

Chironomid larvae

Other*

Mites

Cladocerans

*Insects, spiders, fish, snails.

\section{Percentage of food item in gut}

$$
34.9 \%
$$

$32.63 \%$

$11.43 \%$

$16.98 \%$

$2.36 \%$

$1.68 \%$ 
Table 2. Summary of field experiments conducted during this study.

\begin{tabular}{|c|c|c|c|}
\hline & Preliminary & Wet season & Dry season \\
\hline Location & Taylor Slough & Taylor Slough & Shark Slough \\
\hline Date of experiment & Feb-March 1998 & August 1998 & April 1999 \\
\hline Duration of experiment & 21 days & 18 days & 25 days \\
\hline Grazer-exclusion bags used? & No & Yes & Yes \\
\hline Hydroperiod effects tested? & No & Yes & No \\
\hline Total number of cages $(\mathrm{N})$ & 27 & 54 & 54 \\
\hline Design & $\begin{array}{l}\text { Blocked, full } \\
\text { factorial }(b=3)\end{array}$ & $\begin{array}{l}\text { Full factorial } \\
\text { Paired differences } \\
\text { for hydroperiod effects }\end{array}$ & $\begin{array}{l}\text { Blocked, full } \\
\text { factorial }(b=2)\end{array}$ \\
\hline
\end{tabular}


Table 3. Site descriptions for the field experiments. Values represent averages of the total number of cages for each site. Numbers in parentheses represent standard deviations. "Chl. a" denotes chlorophyll a.

\begin{tabular}{lccrr}
\hline \hline Experiment & Water depth $(\mathbf{c m})$ & Chl. a $\left(\mu \mathrm{g} / \mathbf{m}^{2}\right)$ & AFDM $\left(\mathbf{g} / \mathbf{m}^{2}\right)$ & Lat./Long. \\
\hline Preliminary & 59.5 & $19501(5571)$ & $20.3(3.8)$ & $\begin{array}{l}\text { N25 } 25^{\circ} 19.237^{\prime} \\
\text { W80 38.540 }\end{array}$
\end{tabular}

Wet season

\begin{tabular}{|c|c|c|c|c|}
\hline MDS & 48.0 & $27755(4470)$ & $41.1(4.0)$ & $\begin{array}{l}N_{2} 25^{\circ} 19.887^{\prime} \\
\text { W80 } 37.923^{\prime}\end{array}$ \\
\hline MDL & 50.5 & $25846(5850)$ & $33.6(3.6)$ & $\begin{array}{l}\text { N25 } 19.237^{\prime} \\
\text { W80 } \\
\end{array}$ \\
\hline IMS & 35.0 & $23349(4731)$ & $34.5(2.5)$ & $\begin{array}{l}\text { N25 } 25^{\circ} 17.669^{\prime} \\
\text { W } 80^{\circ} 39.758^{\prime}\end{array}$ \\
\hline IML & 45.5 & $28342(6686)$ & $35.0(4.9)$ & $\begin{array}{l}\mathrm{N}^{2} 5^{\circ} 17.513^{\prime} \\
\mathrm{W} 80^{\circ} 39.749^{\prime}\end{array}$ \\
\hline TSS & 44.0 & $24523(5822)$ & $43.0(3.6)$ & $\begin{array}{l}\mathrm{N} 25^{\circ} 16.607^{\prime} \\
\mathrm{W} 80^{\circ} 41.190^{\prime}\end{array}$ \\
\hline TSL & 45.0 & $27460(3869)$ & $40.6(4.2)$ & $\begin{array}{l}\mathrm{N}^{2} 5^{\circ} 16.272^{\prime} \\
\mathrm{W} 80^{\circ} 40.855^{\prime}\end{array}$ \\
\hline
\end{tabular}

Dry season

\begin{tabular}{|c|c|c|c|c|}
\hline Site A & 43.5 & $32258(3404)$ & $55.2(4.3)$ & $\begin{array}{l}\text { N2 } 25^{\circ} 38.005^{\prime} \\
W 80^{\circ} 43.331^{\prime}\end{array}$ \\
\hline Site B & 43.0 & $34950(7362)$ & $55.4(4.4)$ & $\begin{array}{l}\mathrm{N}^{2} 5^{\circ} 38.005^{\prime} \\
\text { W8 } 80^{\circ} 43.331^{\prime}\end{array}$ \\
\hline
\end{tabular}


Table 4. Summary of treatments for the field experiments. The numbers represent the number of replicates. In (A), numbers in parentheses represent replicates for the short hydroperiod sites of the Wet season experiment. These sites had fewer replicates because 3 cages tipped over due to strong wind gusts.

A) Summary of treatments for the Preliminary and Wet season experiment

\section{Shrimp density}

\begin{tabular}{lllll} 
& & $\mathbf{0}$ & $\mathbf{2 0}$ & $\mathbf{6 0}$ \\
\hline Mosquitofish density & $\mathbf{0}$ & $3(3)$ & $3(2)$ & $3(3)$ \\
& $\mathbf{3}$ & $3(3)$ & $3(2)$ & $3(3)$ \\
& $\mathbf{9}$ & $3(2)$ & $3(3)$ & $3(3)$
\end{tabular}

B) Summary of treatments for the Dry experiment

\section{Shrimp density}

\begin{tabular}{ccccc} 
& & $\mathbf{0}$ & $\mathbf{2 0}$ & $\mathbf{6 0}$ \\
\hline & $\mathbf{0}$ & 6 & 6 & 6 \\
Mosquitofish density & $\mathbf{5}$ & 6 & 6 & 6 \\
& $\mathbf{1 5}$ & 6 & 6 & 6 \\
\hline
\end{tabular}


Table 5. ANOVA tables for Preliminary experiment

A) Dependent variable: wet weight. Model $R^{2}=0.73$

\begin{tabular}{llllll} 
Source & df & MS & $F$ & $P$ & CD $\dagger$ \\
\hline Block (site) & 2 & 0.035 & 7.336 & 0.005 & 0.25 \\
Shrimp density & 2 & 0.046 & 9.601 & 0.002 & 0.33 \\
Fish density & 2 & 0.017 & 3.605 & 0.051 & 0.12 \\
Shrimp x Fish & 4 & 0.002 & 0.352 & 0.839 &
\end{tabular}

Error $\quad 16 \quad 0.005$

B) Dependent variable: Chlorophyll a. Model $R^{2}=0.65$

$\begin{array}{llllll}\text { Block (site) } & 2 & 0.162 & 3.539 & 0.053 & \\ \text { Shrimp density } & 2 & 0.295 & 6.432 & 0.009 & 0.28 \\ \text { Fish density } & 2 & 0.077 & 1.675 & 0.219 & \\ \text { Shrimp x Fish } & 4 & 0.069 & 1.497 & 0.250 & \\ \text { Error } & 16 & 0.046 & & & \end{array}$

C) Dependent variable: AFDM. Model $R^{2}=0.54$

$\begin{array}{lllll}\text { Block (site) } & 2 & 0.156 & 3.220 & 0.067 \\ \text { Shrimp density } & 2 & 0.091 & 1.880 & 0.185 \\ \text { Fish density } & 2 & 0.029 & 0.608 & 0.557 \\ \text { Shrimp x Fish } & 4 & 0.087 & 1.802 & 0.178 \\ \text { Error } & 16 & 0.048 & & \end{array}$

$\dagger$ Coefficient of determination (see Methods: Statistical analyses) 
Table 6. T-test statistics of control treatments for cages and bags. Control treatments refer to zero densities of both consumers.

A) Wet season experiment

\begin{tabular}{lllllllll} 
& \multicolumn{3}{c}{ Short hydroperiod sites } & & & \multicolumn{3}{c}{ Long hydroperiod sites } \\
\cline { 2 - 3 } \cline { 8 - 9 } Variable & t-statistic & df & $P$ & & t-statistic & df & $P$ \\
\hline Wet weight & -0.989 & 2 & 0.427 & & -3.077 & 2 & 0.091 \\
Chlorophyll a & -0.777 & 2 & 0.518 & & -1.422 & 2 & 0.291 \\
AFDM & -1.845 & 2 & 0.206 & & -2.646 & 2 & 0.118
\end{tabular}

B. Dry season experiment

\begin{tabular}{lccc} 
Variable & $\mathrm{t}$-statistic & $\mathrm{df}$ & $P$ \\
\hline Wet weight & -1.056 & 5 & 0.339 \\
Chlorophyll a & -0.822 & 5 & 0.448 \\
AFDM & -0.169 & 5 & 0.872 \\
\hline
\end{tabular}


Table 7. Mean periphyton proportion change in bags and cages for the Wet season experiment

\begin{tabular}{lccc}
\multicolumn{2}{l}{ A) Long hydroperiod sites } & & \\
Compartment & Wet weight & Chlorophyll a & AFDM \\
\hline Bag & 0.105 & 1.021 & 0.905 \\
Cage & -0.102 & 0.733 & 0.503 \\
B) Short hydroperiod sites & & \\
Bag & 0.074 & & \\
Cage & -0.059 & 0.509 & 0.776 \\
\hline
\end{tabular}


Table 8. ANOVA tables for separate analyses of cages and bags for the Wet season experiment

A) Dependent variable: wet weight in cages for long hydroperiod. Model $R^{2}=0.56$

\begin{tabular}{llllll} 
Source & df & MS & $F$ & $P$ & $\mathrm{CD} \dagger$ \\
\hline Shrimp density & 2 & 0.037 & 4.480 & 0.026 & 0.22 \\
Fish density & 2 & 0.006 & 0.772 & 0.477 & \\
Shrimp x Fish & 4 & 0.025 & 3.041 & 0.044 & 0.30 \\
Error & 18 & 0.008 & & &
\end{tabular}

B) Dependent variable: AFDM in cages for short hydroperiod. Model $R^{2}=0.39$

$\begin{array}{llllll}\text { Shrimp density } & 2 & 0.287 & 3.701 & 0.049 & 0.30 \\ \text { Fish density } & 2 & 0.032 & 0.409 & 0.671 & \\ \text { Shrimp x Fish } & 4 & 0.038 & 0.495 & 0.740 & \\ \text { Error } & 15 & 0.078 & & & \end{array}$

C) Dependent variable: AFDM in bags for short hydroperiod. Model $R^{2}=0.49$

$\begin{array}{llllll}\text { Shrimp density } & 2 & 0.262 & 4.064 & 0.039 & 0.28 \\ \text { Fish density } & 2 & 0.067 & 1.034 & 0.380 & \\ \text { Shrimp x Fish } & 4 & 0.066 & 1.021 & 0.428 & \\ \text { Error } & 15 & 0.064 & & & \end{array}$

D) Dependent variable: AFDM in bags for long hydroperiod. Model $R^{2}=0.42$

$\begin{array}{llllll}\text { Shrimp density } & 2 & 0.143 & 1.680 & 0.214 & \\ \text { Fish density } & 2 & 0.289 & 3.392 & 0.056 & 0.22 \\ \text { Shrimp x Fish } & 4 & 0.061 & 0.715 & 0.592 & \\ \text { Error } & 18 & 0.085 & & & \end{array}$

$\dagger$ Coefficient of determination (see Methods: Statistical analyses) 
Table 9. Mean periphyton proportion change in bags and cages for the Dry season experiment (untransformed variables)

\begin{tabular}{lcccc}
\hline \hline Compartment & Wet weight & Chlorophyll a & AFDM & TP \\
\hline Bag & 0.157 & 0.134 & -0.050 & -0.245 \\
Cage & -0.035 & 0.048 & -0.139 & -0.228 \\
\hline
\end{tabular}


Figure 1. Predicted scenarios for the outcome of periphyton-animal interactions. The xaxis represents increasing consumer density and the $y$-axis represents proportion of periphyton biomass that increases or decreases from an initial biomass value. The use of proportions allows for comparisons between cages and bags. No consumption is indicated by parallel and overlapping trajectories of cage and bag means for periphyton biomass along increasing consumer density (scenario \#1). Consumption in general is indicated if the trajectory of means for the cages is below the trajectory of the bag means (all scenarios, except for \#1). If consumption only is in operation (scenario \#2), means in cages should decrease but bag means should stay constant. If, in addition to consumption, there is nutrient regeneration by the consumers, two different outcomes are possible (scenarios \#3 and \#4). The difference between the two scenarios is the relative strength of consumptive effects relative to nutrient regeneration effects. If consumptive effects are strong relative to nutrient regeneration processes, then scenario \#4 is likely to occur. Conversely, if there are weak consumptive effects relative to nutrient regeneration, then scenario \#3 is more likely to occur. In scenario \#5, consumption is decoupled from physical stimulation, and therefore the trajectory of bag means remains constant whereas the trajectory of cage means increases with increasing grazer density. A trophic cascade, where consumers prey on a strict herbivore feeding on periphyton, would yield scenario \#6. 


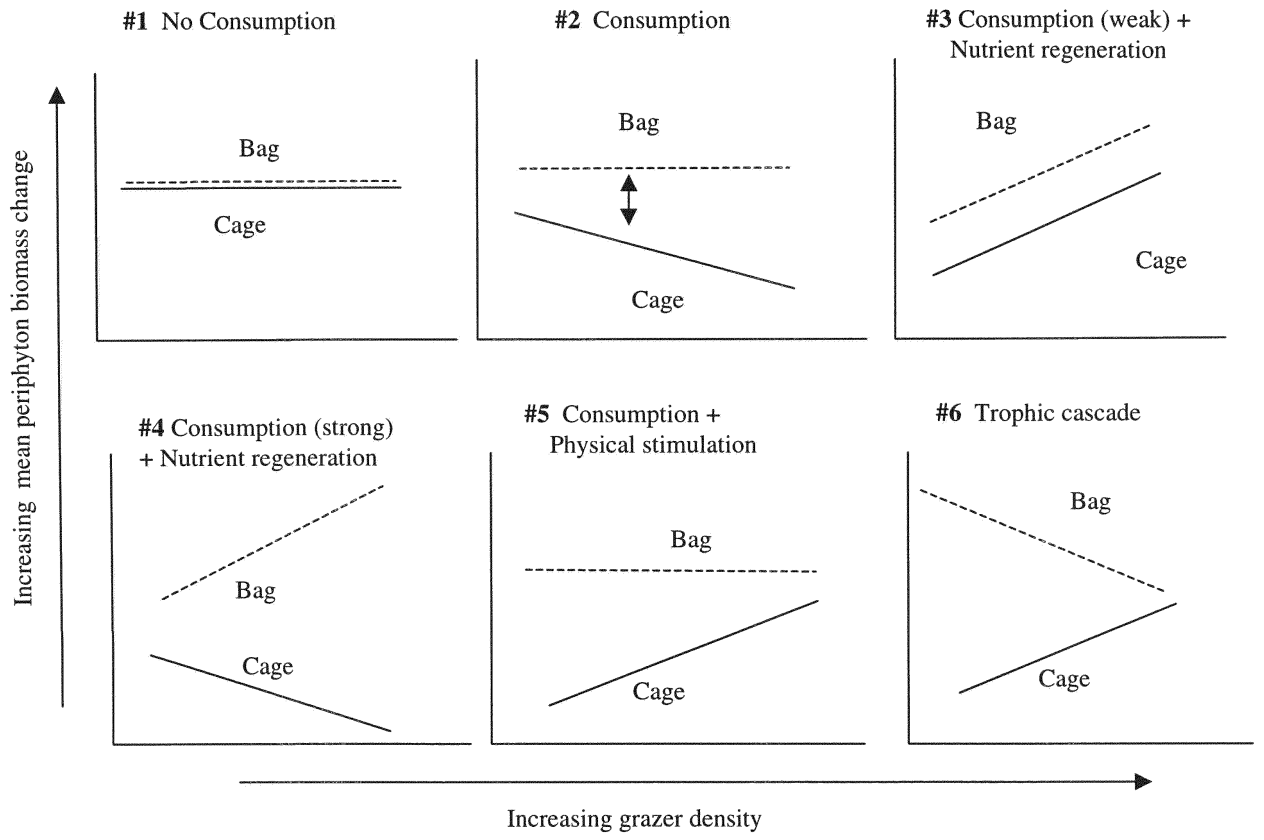


Figure 2. Location of study sites 


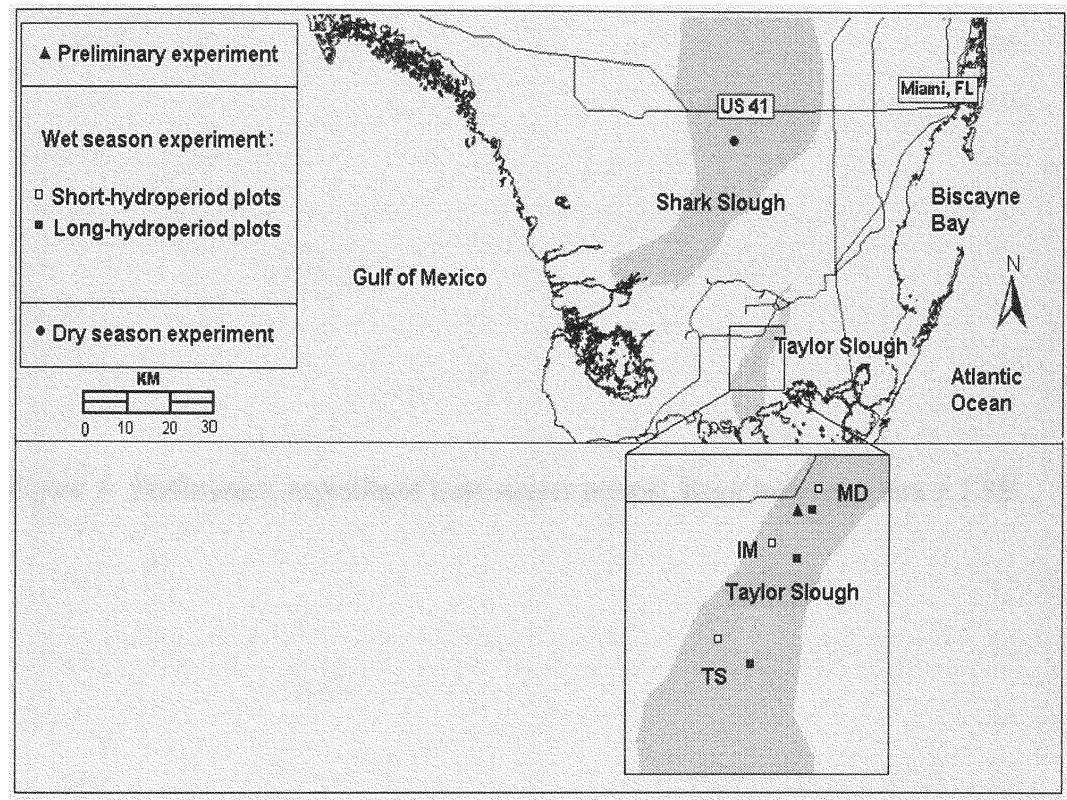


Figure 3. Preliminary experiment least-square means. Error bars represent $\pm 1 \mathrm{SE}$. 


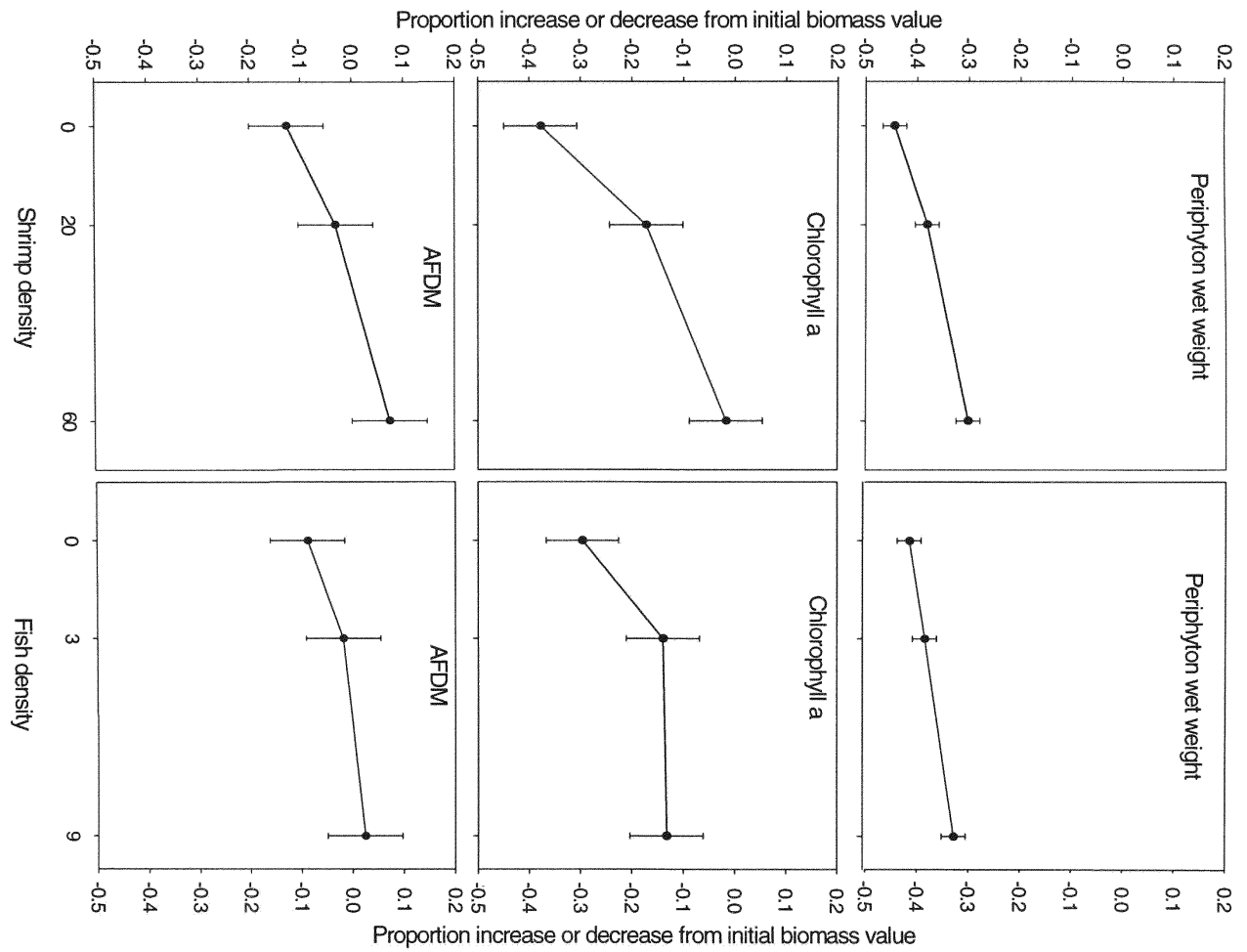


Figure 4. Least-square mean periphyton proportion change for bags and cages of the Wet season experiment. Error bars represent $\pm 1 \mathrm{SE}$. 


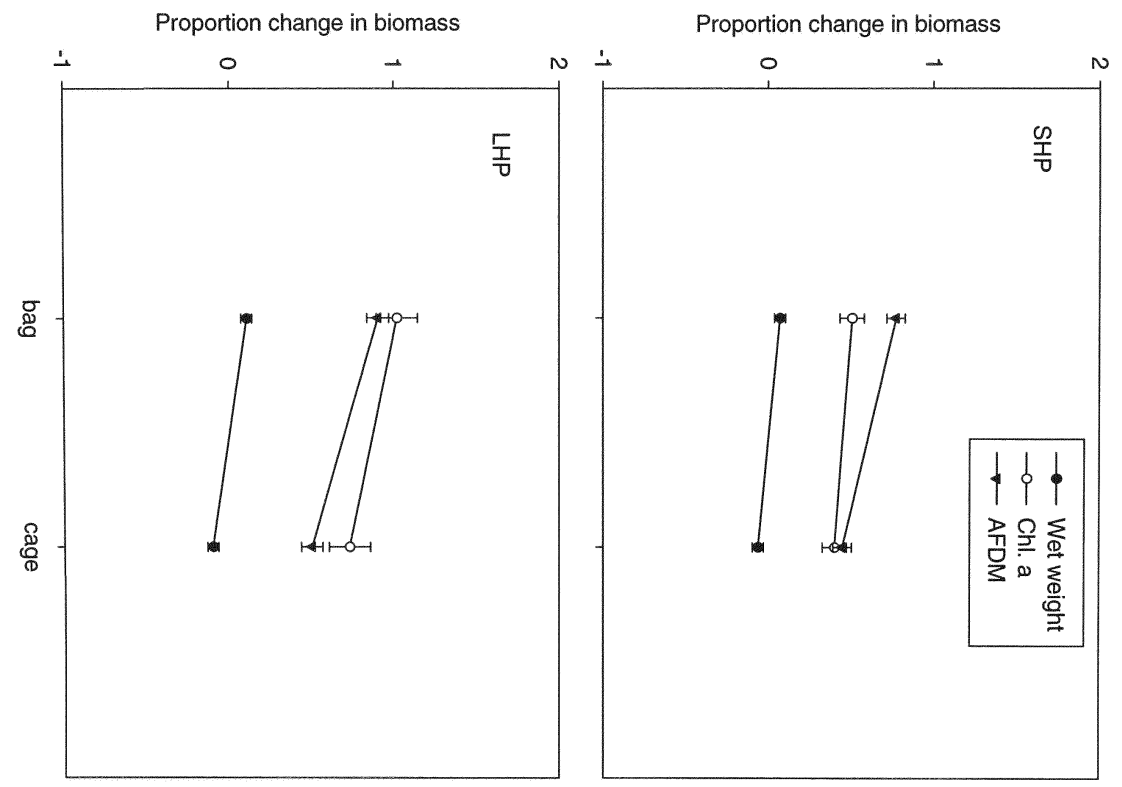


Figure 5. Shrimp density effects for short (SHP) and long (LHP) hydroperiod sites; Wet season experiment. Error bars represent \pm 1 SE. Open dots represent values in bags; solid dots represent values in cages. Note that scale for TP is different. 


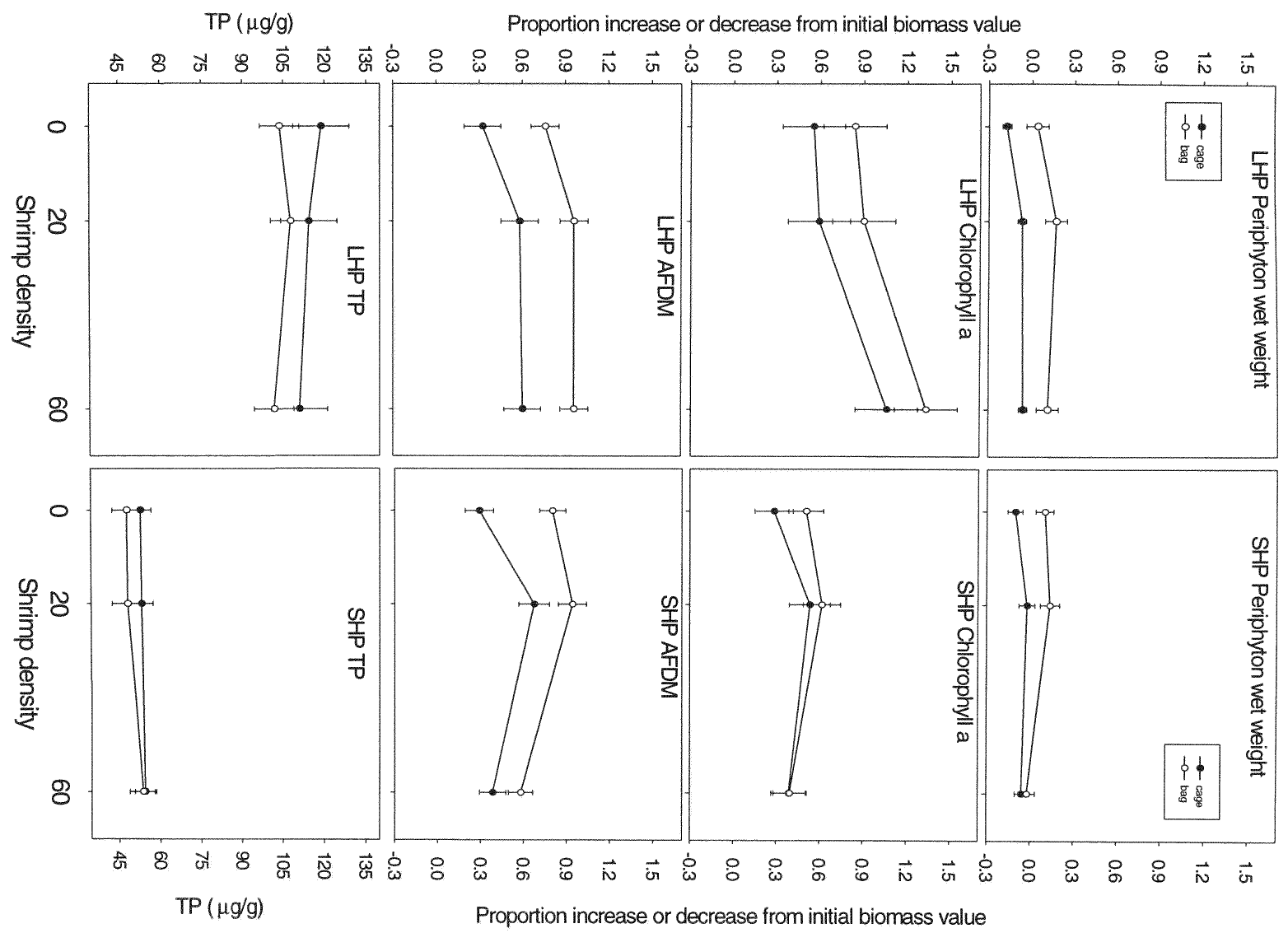


Figure 6. Mosquitofish density effects for short (SHP) and long (LHP) hydroperiod sites; Wet season experiment. Error bars represent \pm 1 SE. Open dots represent values in bags; solid dots represent values in cages. Note that scale for TP is different. 

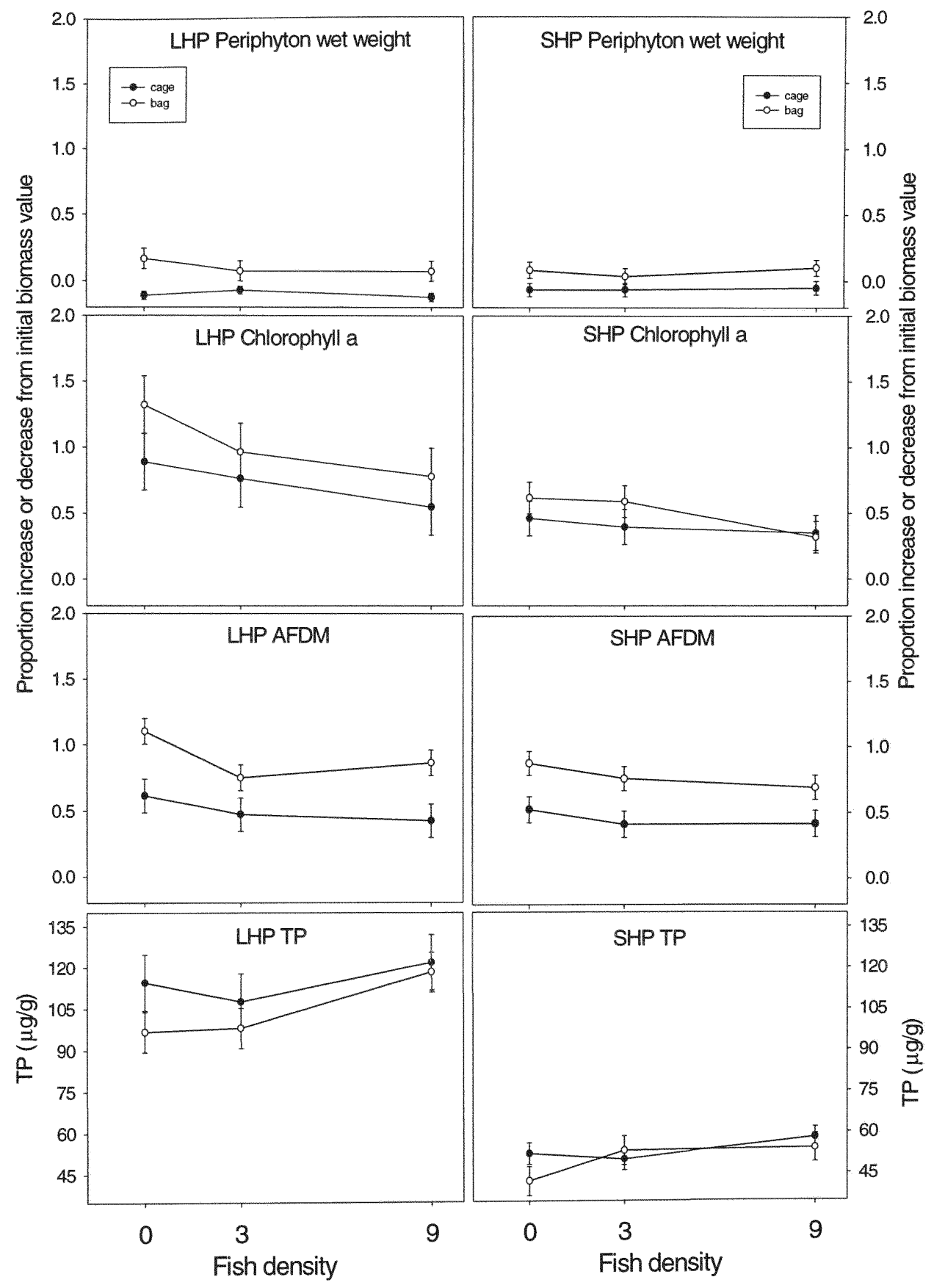
Figure 7. Least-square mean periphyton proportion change for bags and cages of the Dry season experiment (untransformed variables). Error bars represent $\pm 1 \mathrm{SE}$. 


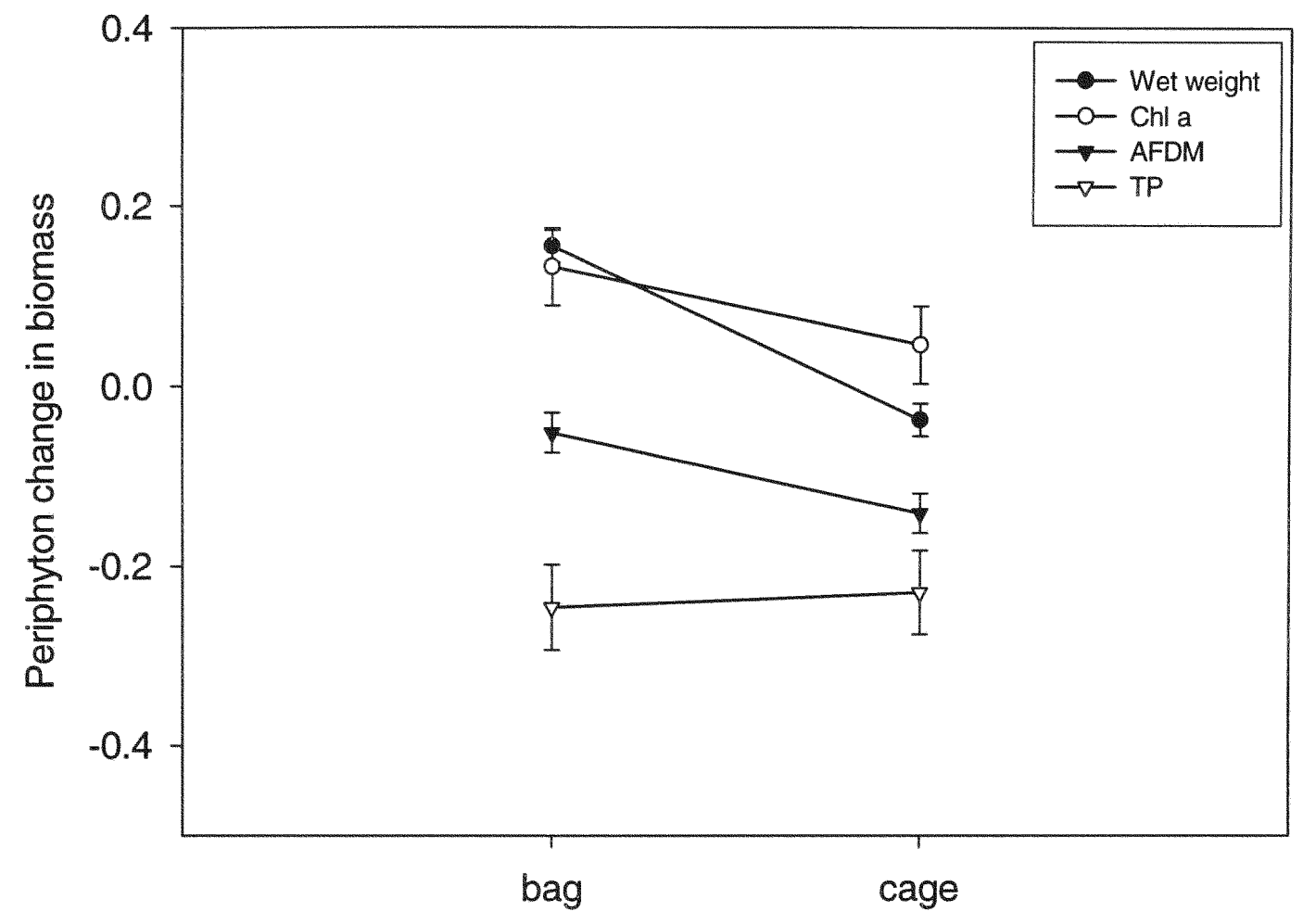


Figure 8. Consumer density effects for the Dry season experiment (untransformed data). Error bars represent $\pm 1 \mathrm{SE}$. Open dots represent values in bags; solid dots represent values in cages. 
Proportion increase or decrease from initial biomass value
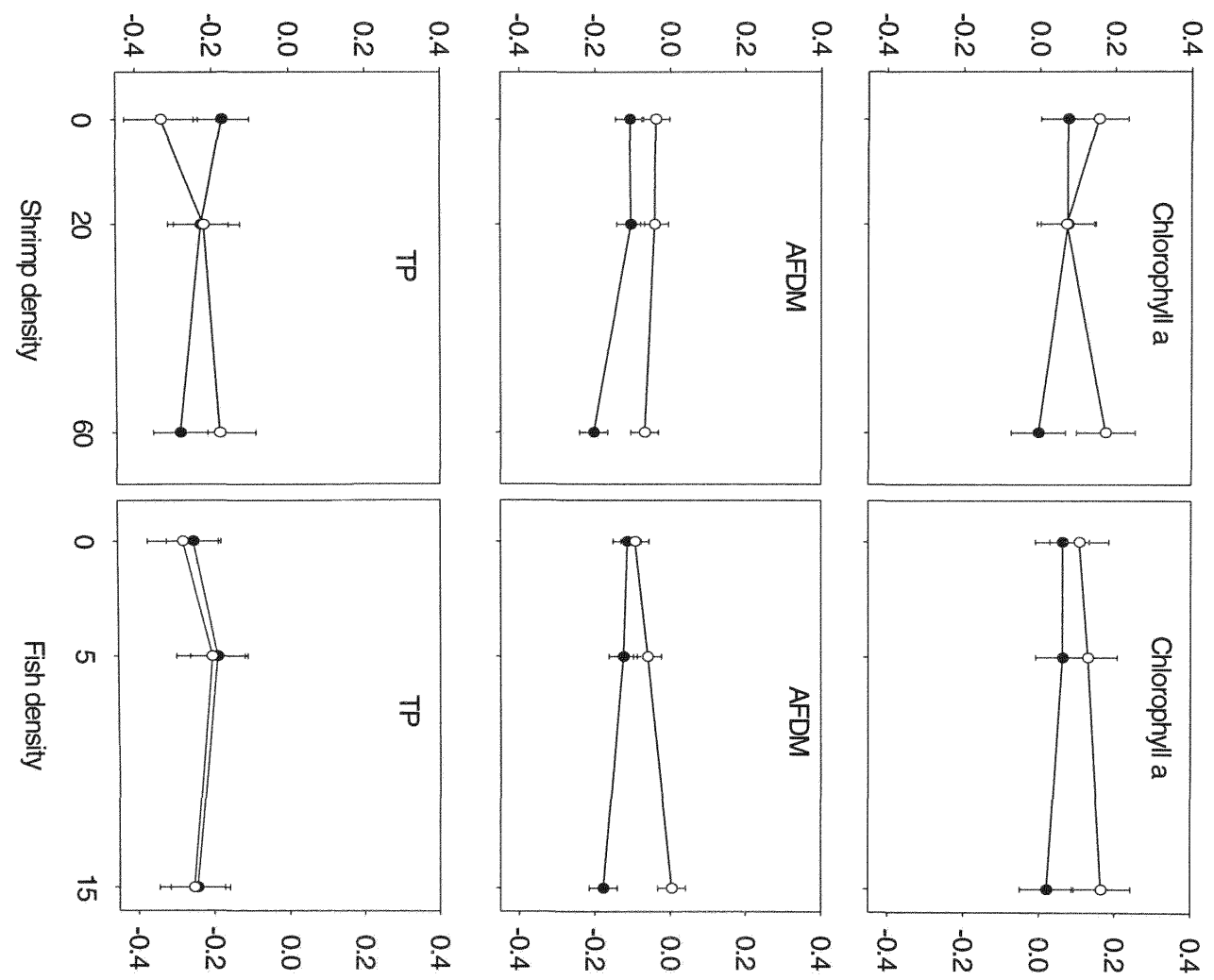

i

Proportion increase or decrease from initial biomass value 
Figure 9. Power for Preliminary experiment, with observed effect sizes and with a hypothetical effect size $=0.5 \mathrm{x}$ control means. Dashed line corresponds to a reference power value of 0.80 . Variables starting with "s" correspond to shrimp density, variables starting with "f" correspond to fish density, and variables starting with " $\mathrm{s} * \mathrm{f}$ ", to the interaction of both consumer densities. Variables named "wetwt" represent wet weight, "chla" represent chlorophyll a, and "afdm" represent ash-free dry mass. 


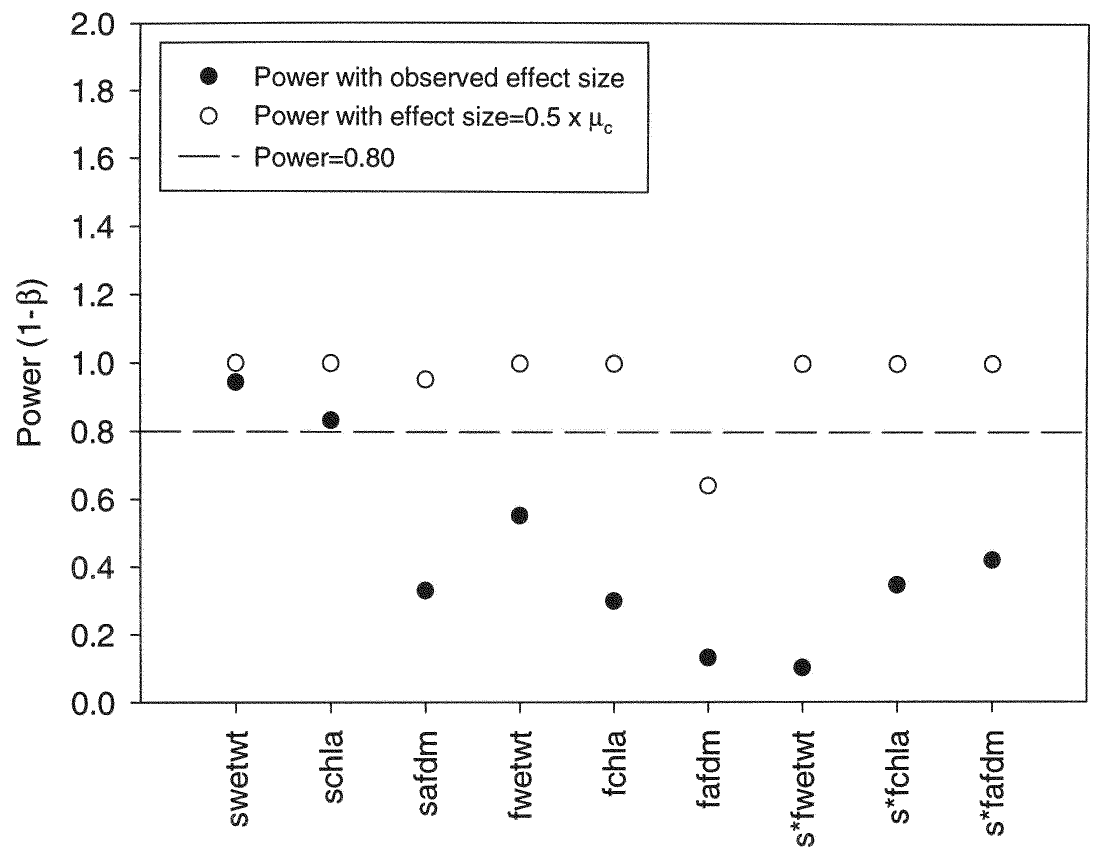


Figure 10. Power for long hydroperiod sites of the Wet season experiment, with observed effect sizes and with a hypothetical effect size $=0.5 \mathrm{x}$ control means. Dashed line corresponds to a reference power value of 0.80 . Variables starting with "s" correspond to shrimp density, variables starting with "f" correspond to fish density, and variables starting with "s*f", to the interaction of both consumer densities. Variables with a "c" before the dependant variable name refer to cage values, and variables with a "b", refer to bag values. Variables named "wetwt" represent wet weight, "chla" represent chlorophyll a, "afdm" represent ash-free dry mass, and "tp" represent total phosphorus. 


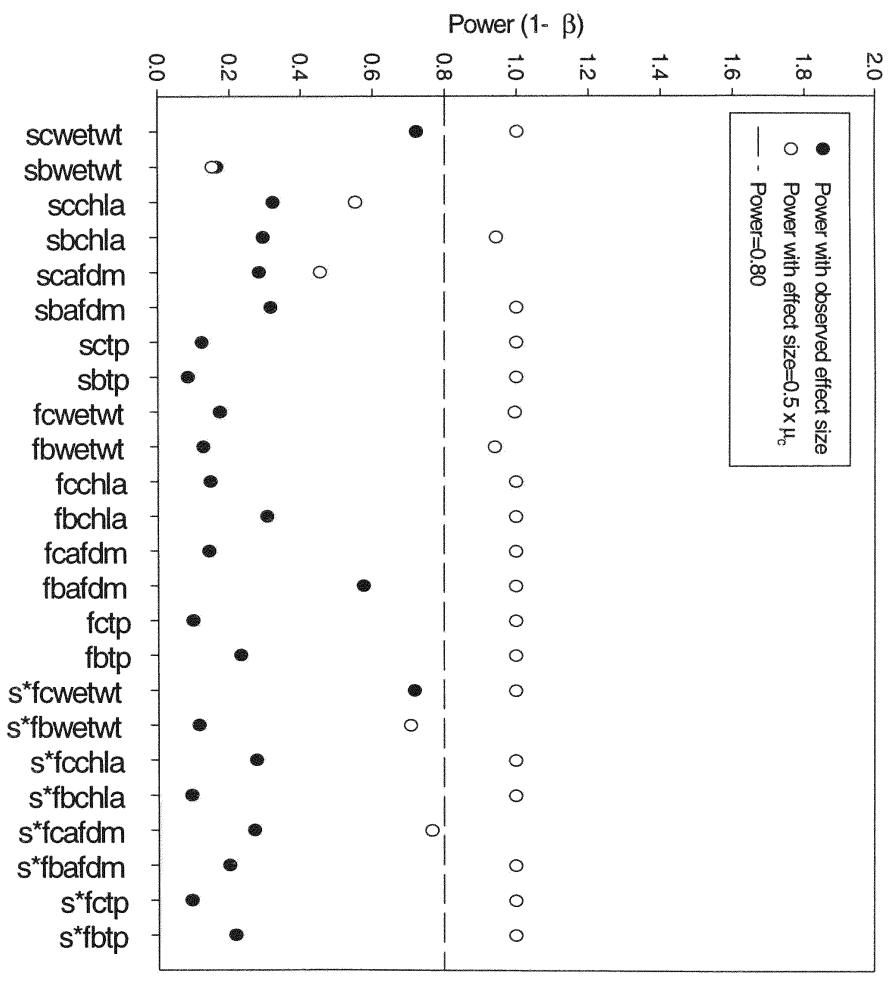


Figure 11. Power for Dry season experiment, with observed effect sizes and with a hypothetical effect size $=0.5 \times$ control means. Dashed line corresponds to a reference power value of 0.80 . Variables starting with "s" correspond to shrimp density, variables starting with "f" correspond to fish density, and variables starting with " $\mathrm{s} * \mathrm{f}$ ", to the interaction of both consumer densities. Variables with a "c" before the dependant variable name refer to cage values, and variables with a "b", refer to bag values. Variables named "wetwt" represent wet weight, "chla" represent chlorophyll a, and "afdm" represent ash-free dry mass. 


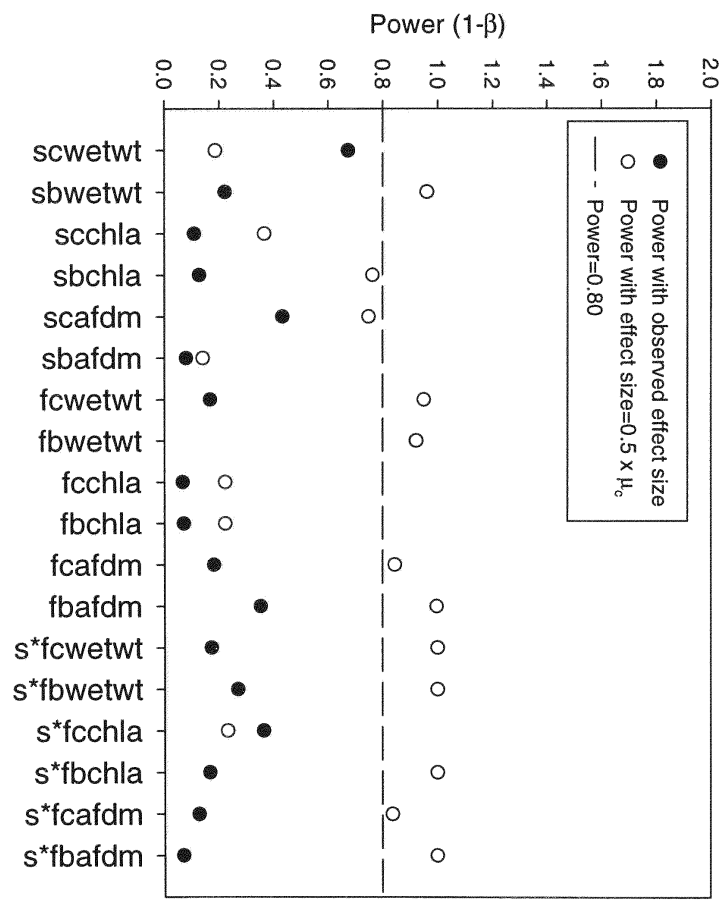


Plate 1. Top plate: Blue-green filaments showing $\mathrm{CaCO}_{3}$ encrustation (Magnification 200X)

Bottom plate: $U$. cornuta inside mat (Magnification 100X) 

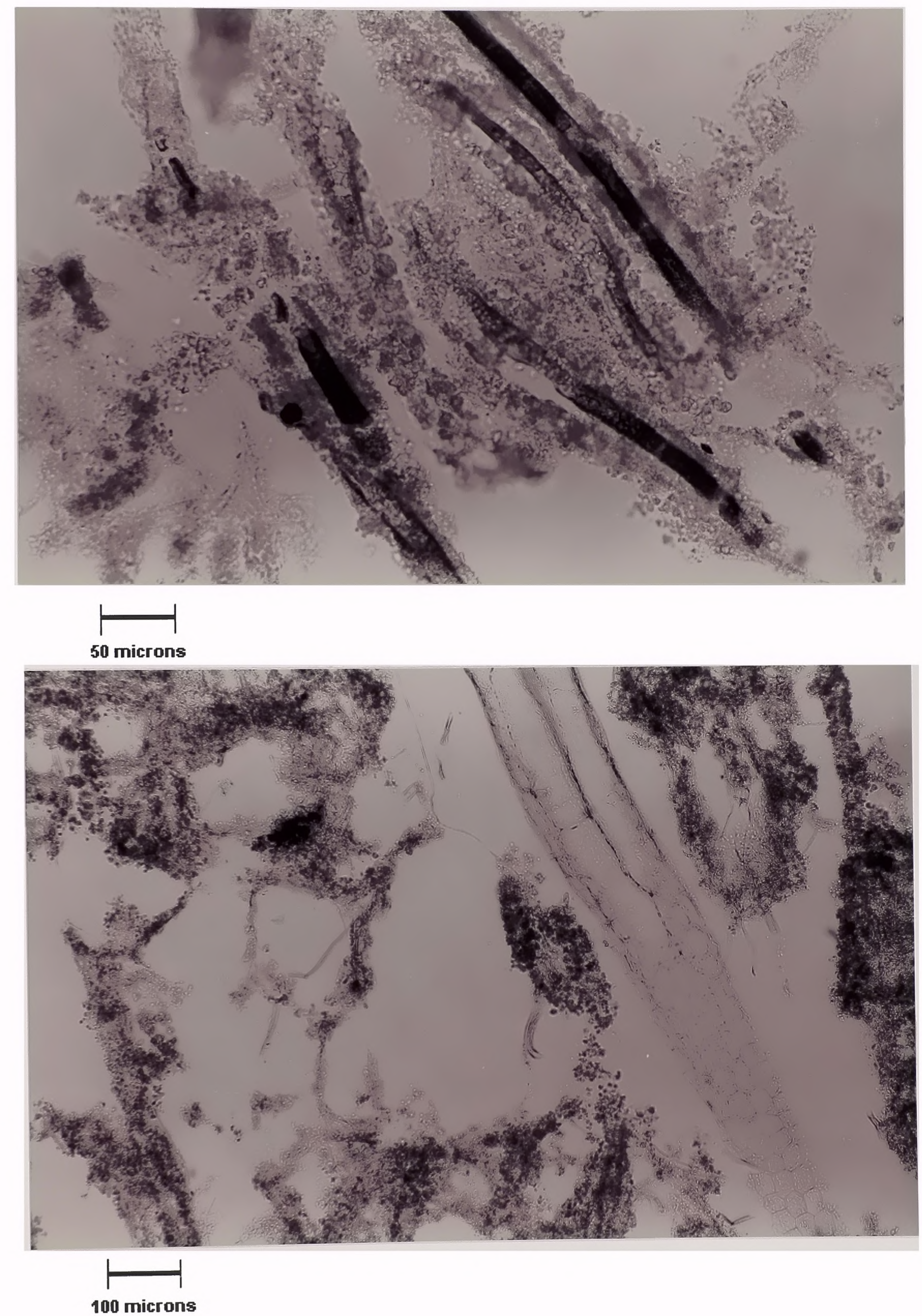
Plate 2. Overall structure of a short-hydroperiod periphyton mat (no magnification)
A. Top section (Magnification 40X; scale bar $=100$ microns)
B. Middle section (Magnification 40X; scale bar $=100$ microns)
C. Bottom section (Magnification 40X; scale bar $=100$ microns) 

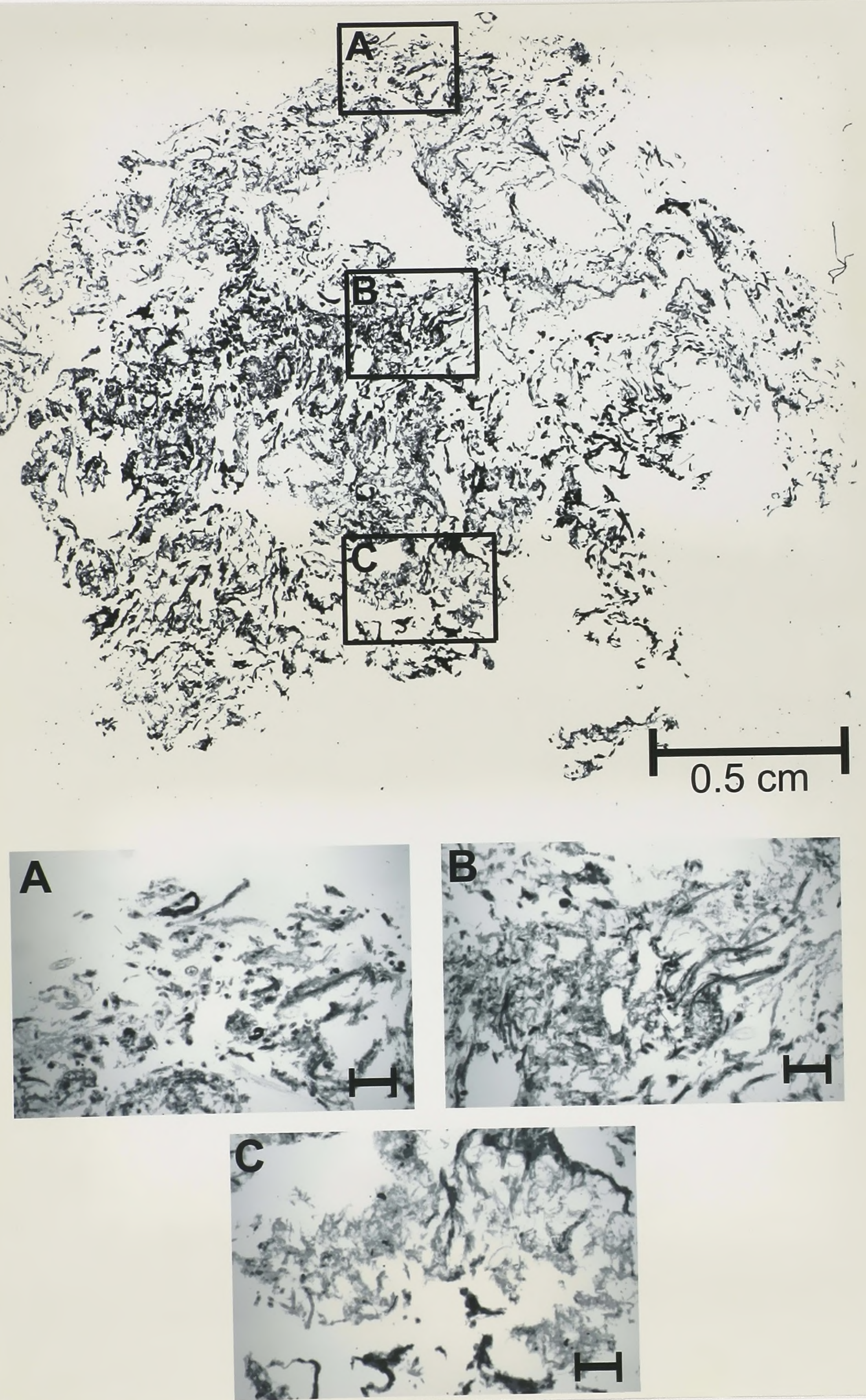


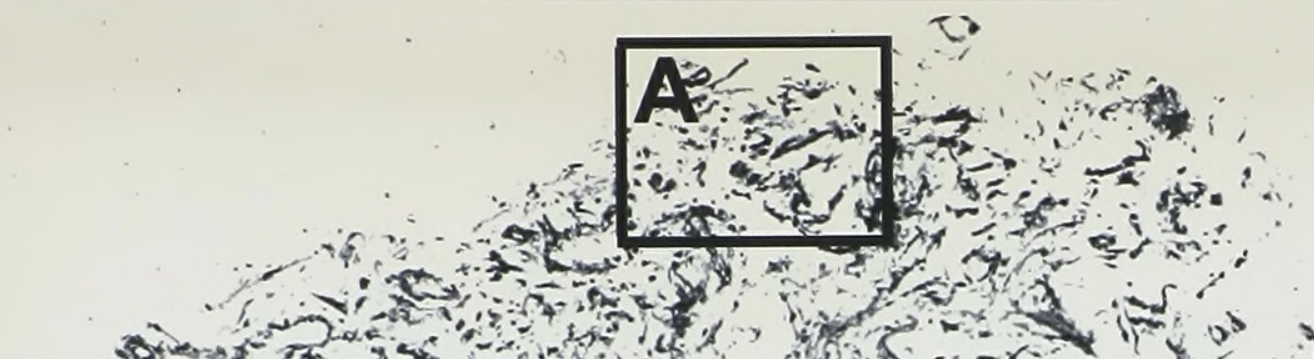

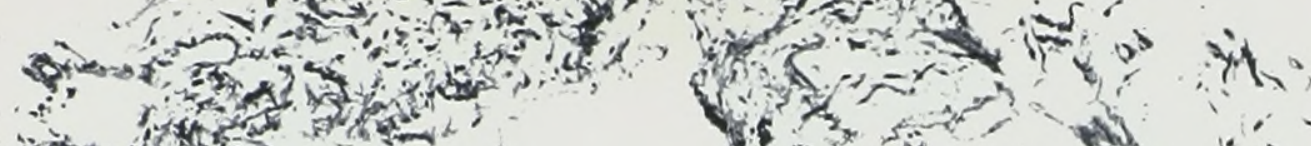
F. 2.

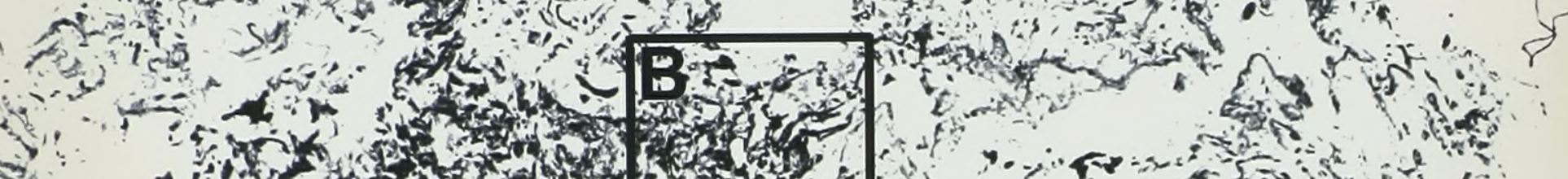
10

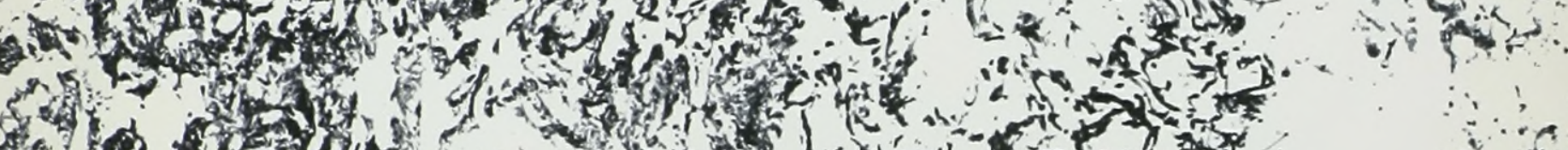
540 ond

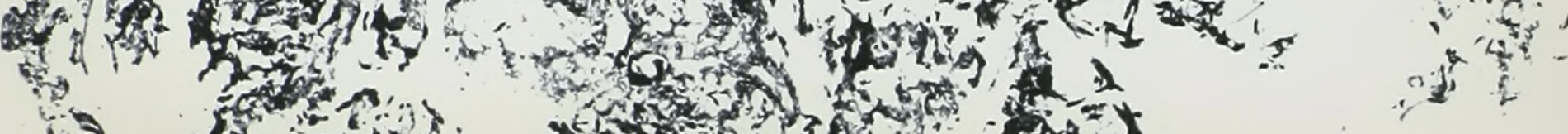

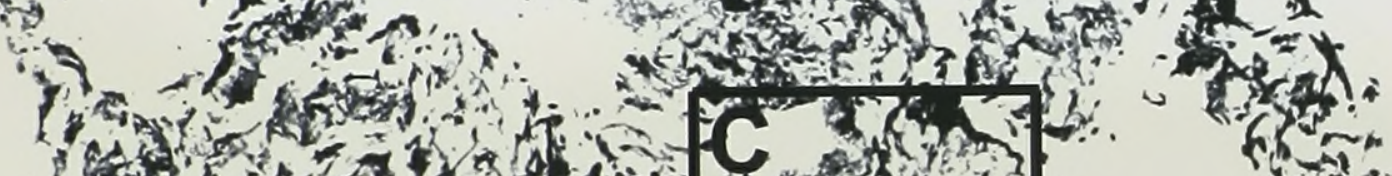

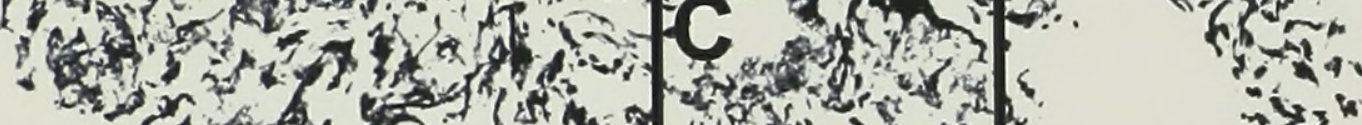

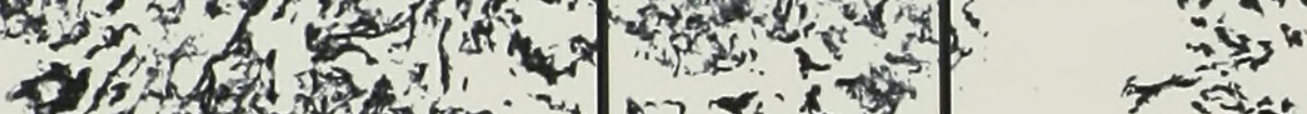

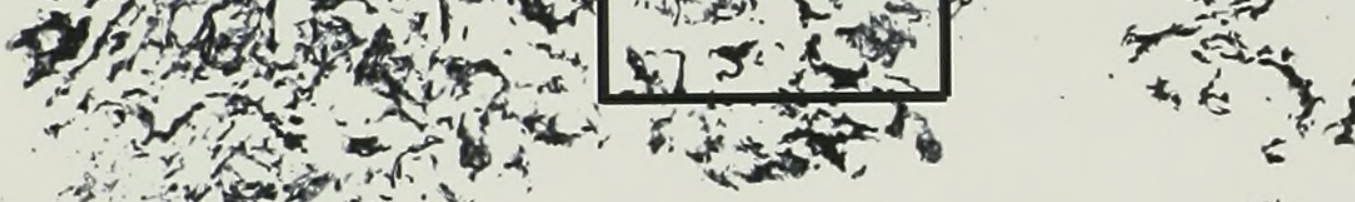
atis $*$ int
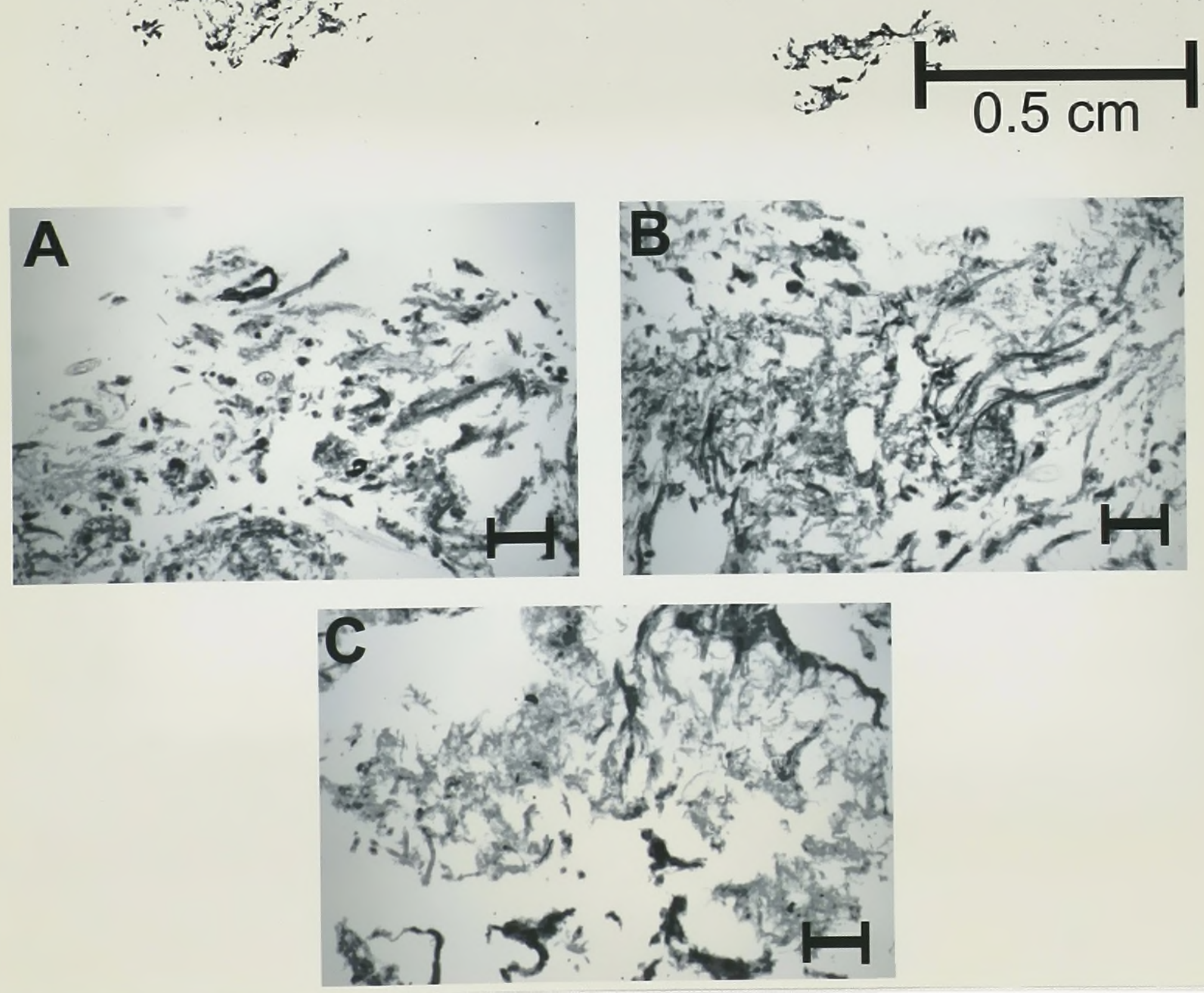

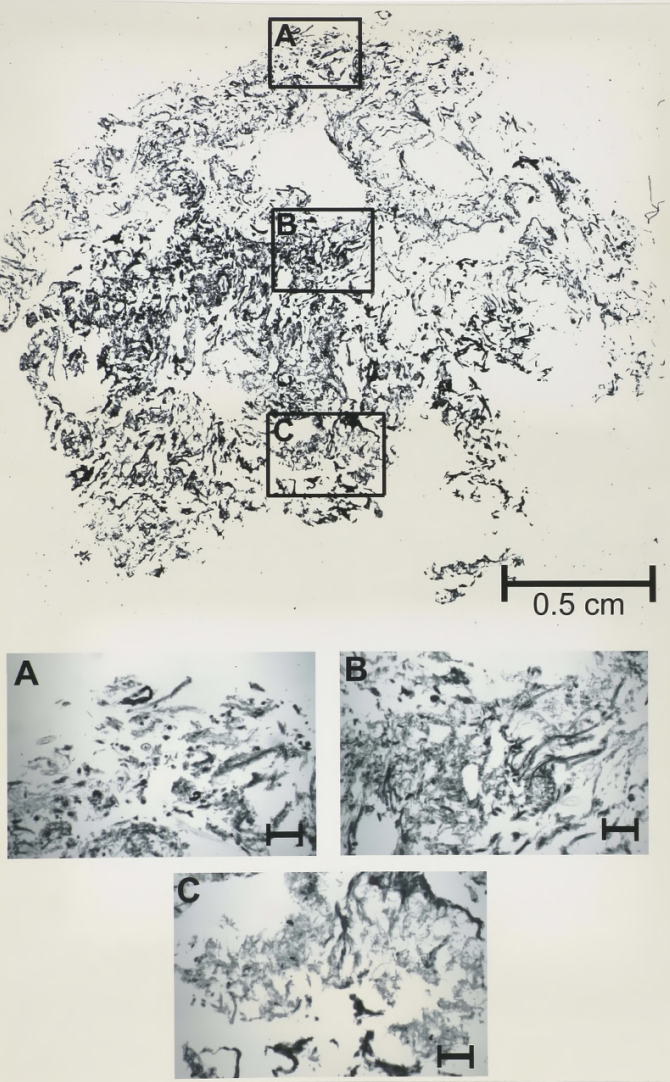

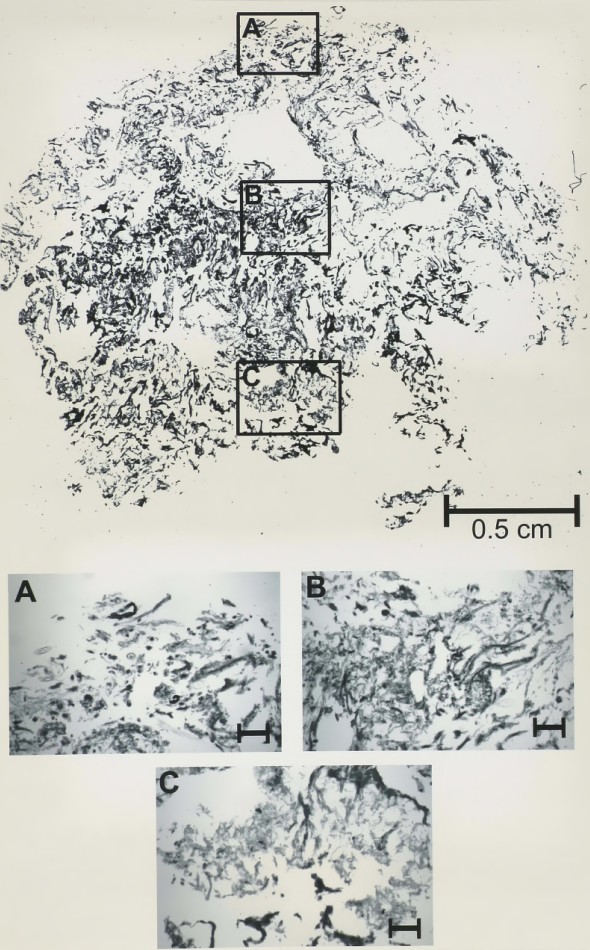

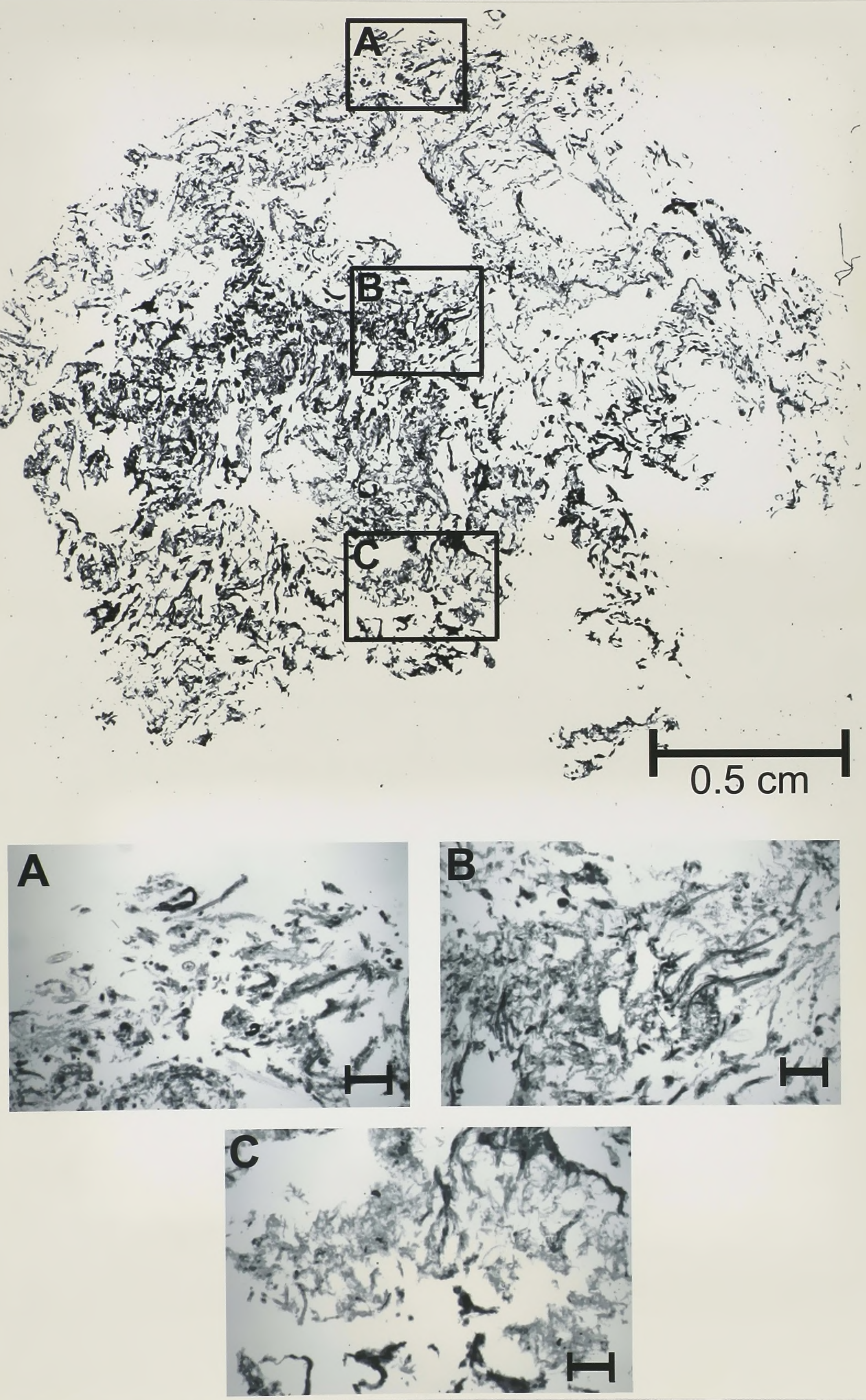

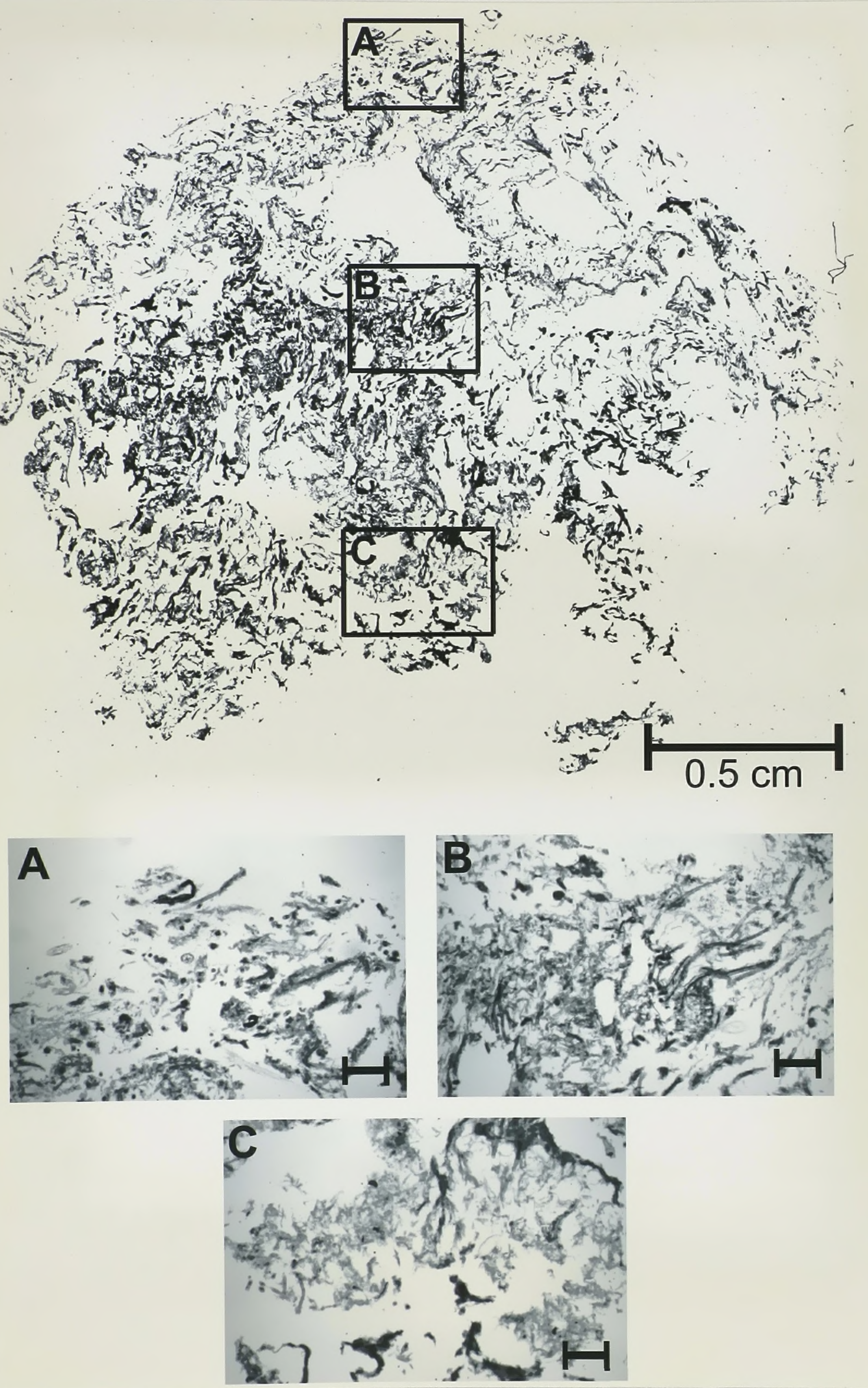
Plate 3. Periphyton mat showing green algae

Top plate: Triploceras spp. (Magnification 200X)

Bottom plate: Cosmarium spp. (Magnification 200X) 
suoงग!ய 05
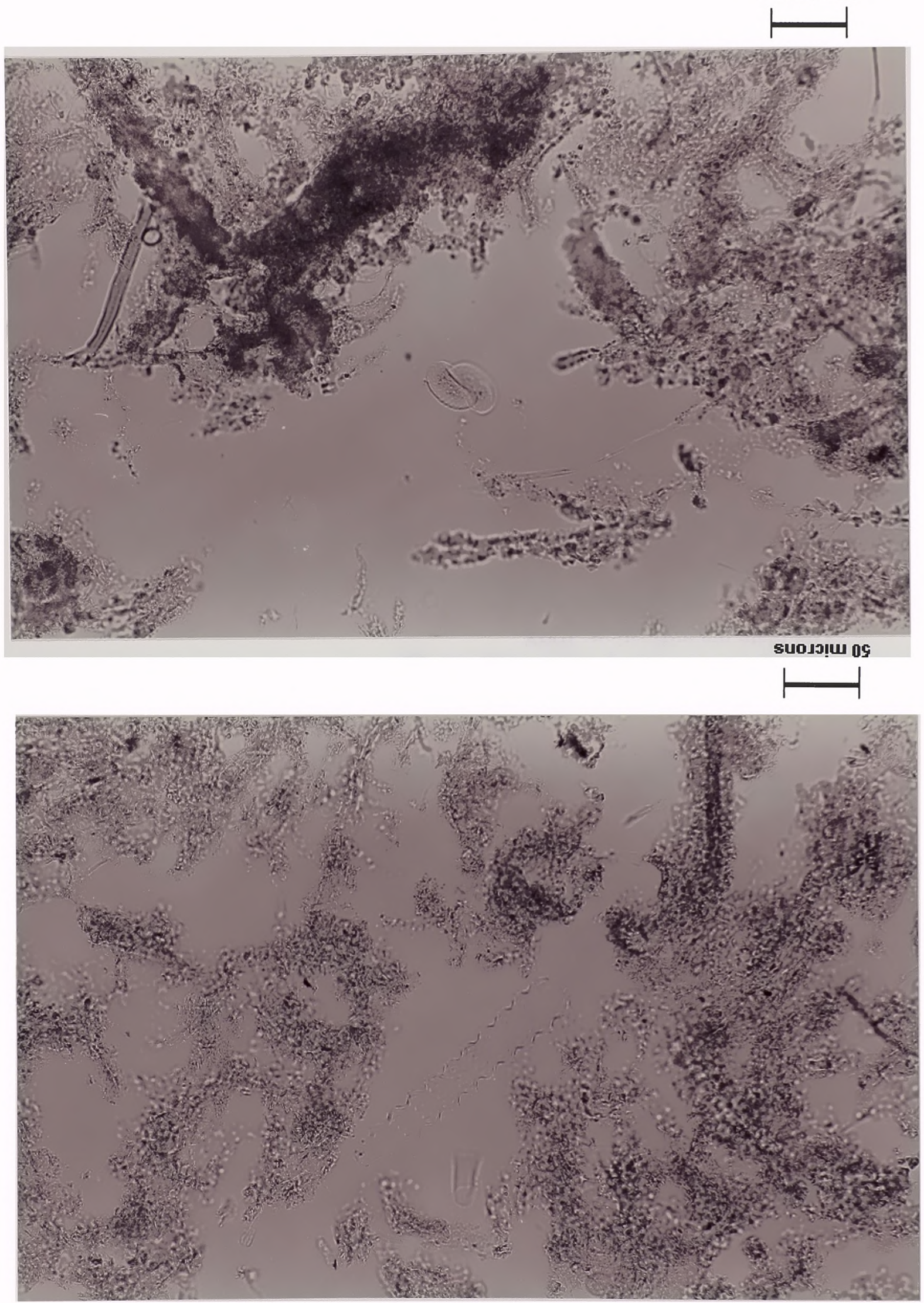
Plate 4. Mites (two different species) inside the mat Top plate magnification: $100 \mathrm{X}$ Bottom plate magnification: $100 \mathrm{X}$ 

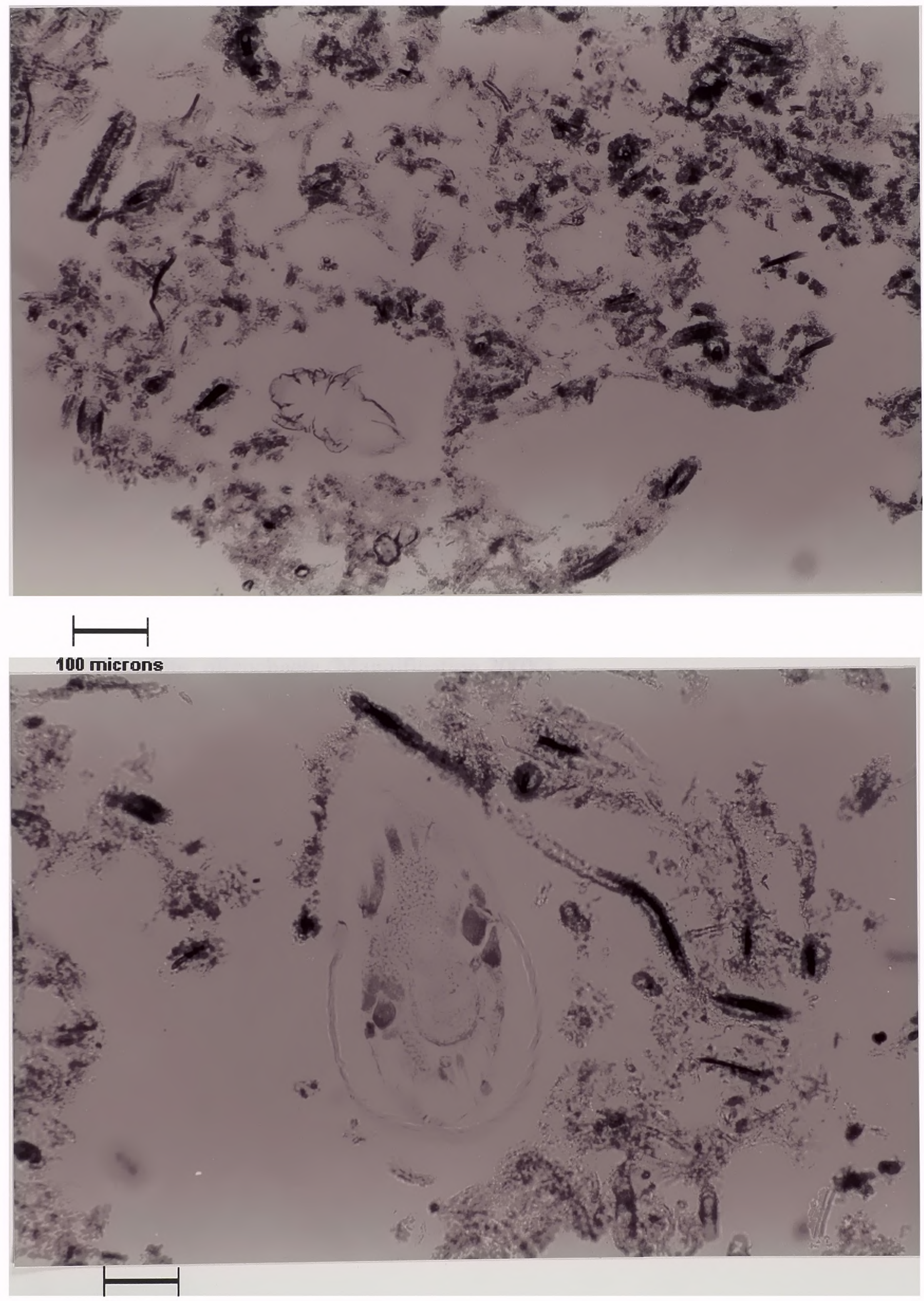

100 microns 
Plate 5. Invertebrates inside the mat

Top plate: oligochaete (Magnification 200X)

Bottom plate: remnants of an insect (Magnification 100X) 
suดงगฺ 001

⺊

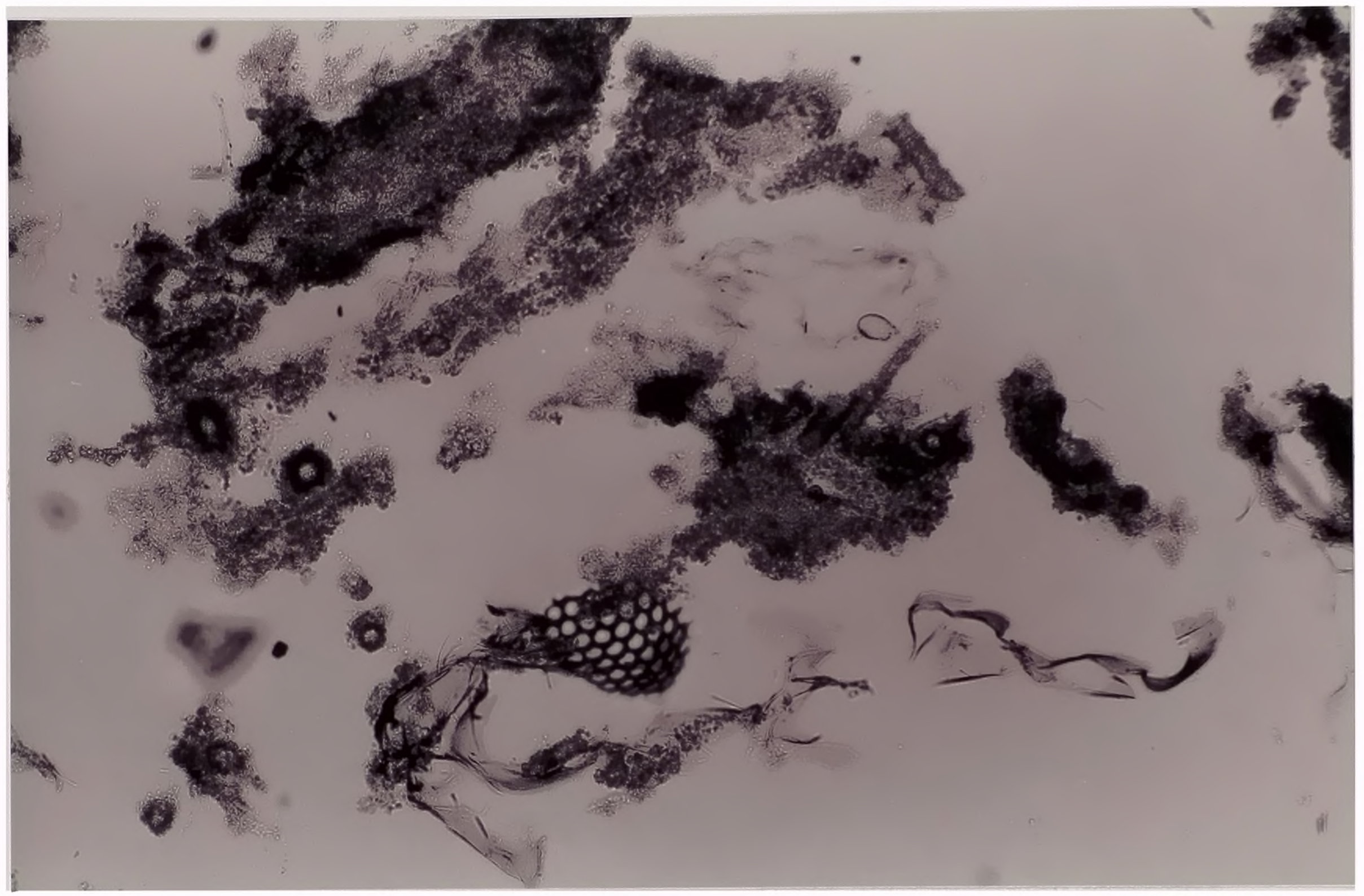

suoงग!ய 0 5

⺊

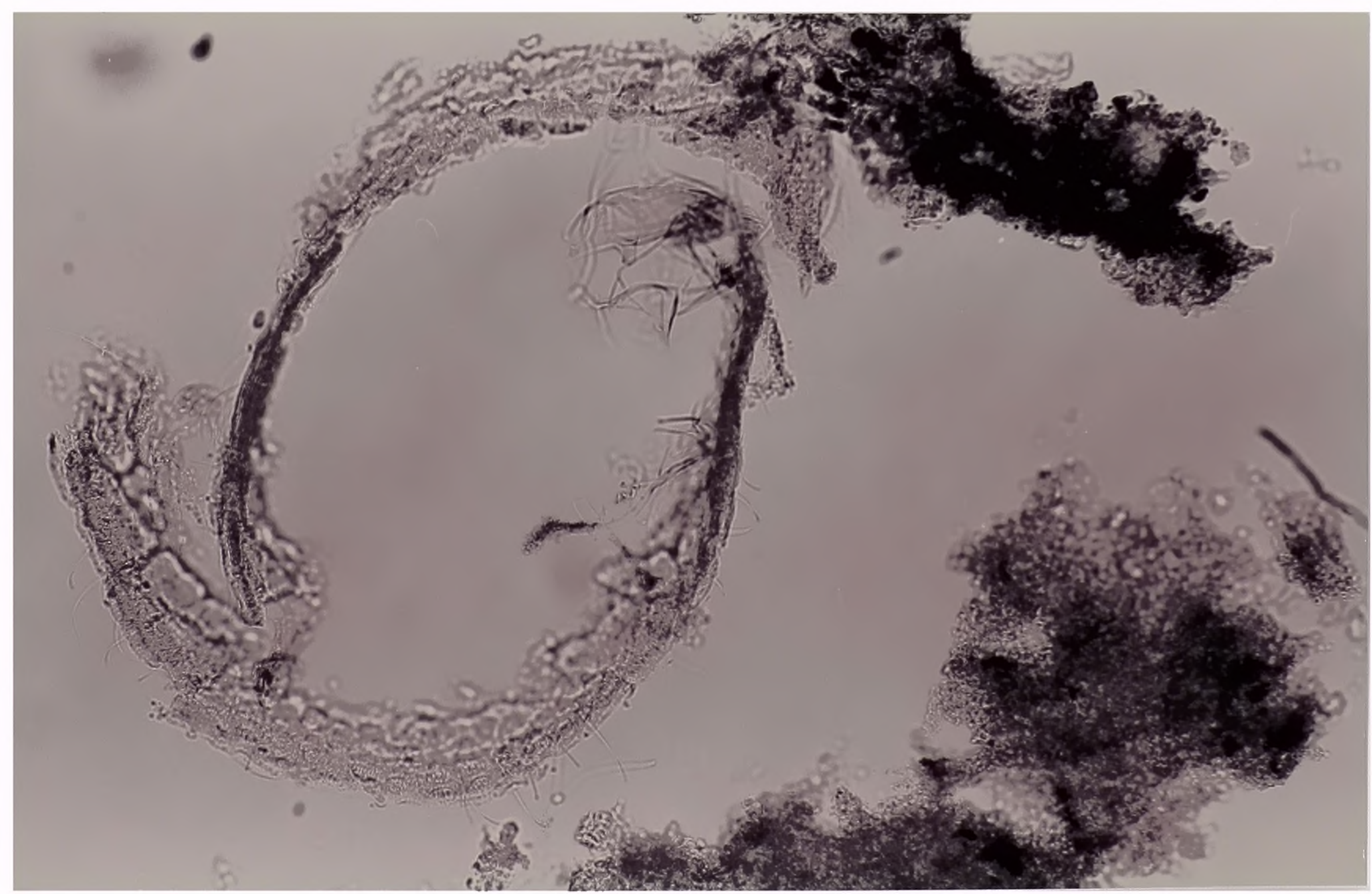


Plate 6. Diatom "pockets" inside the mat Top plate magnification: $200 \mathrm{X}$ Bottom plate magnification: $400 \mathrm{X}$ 

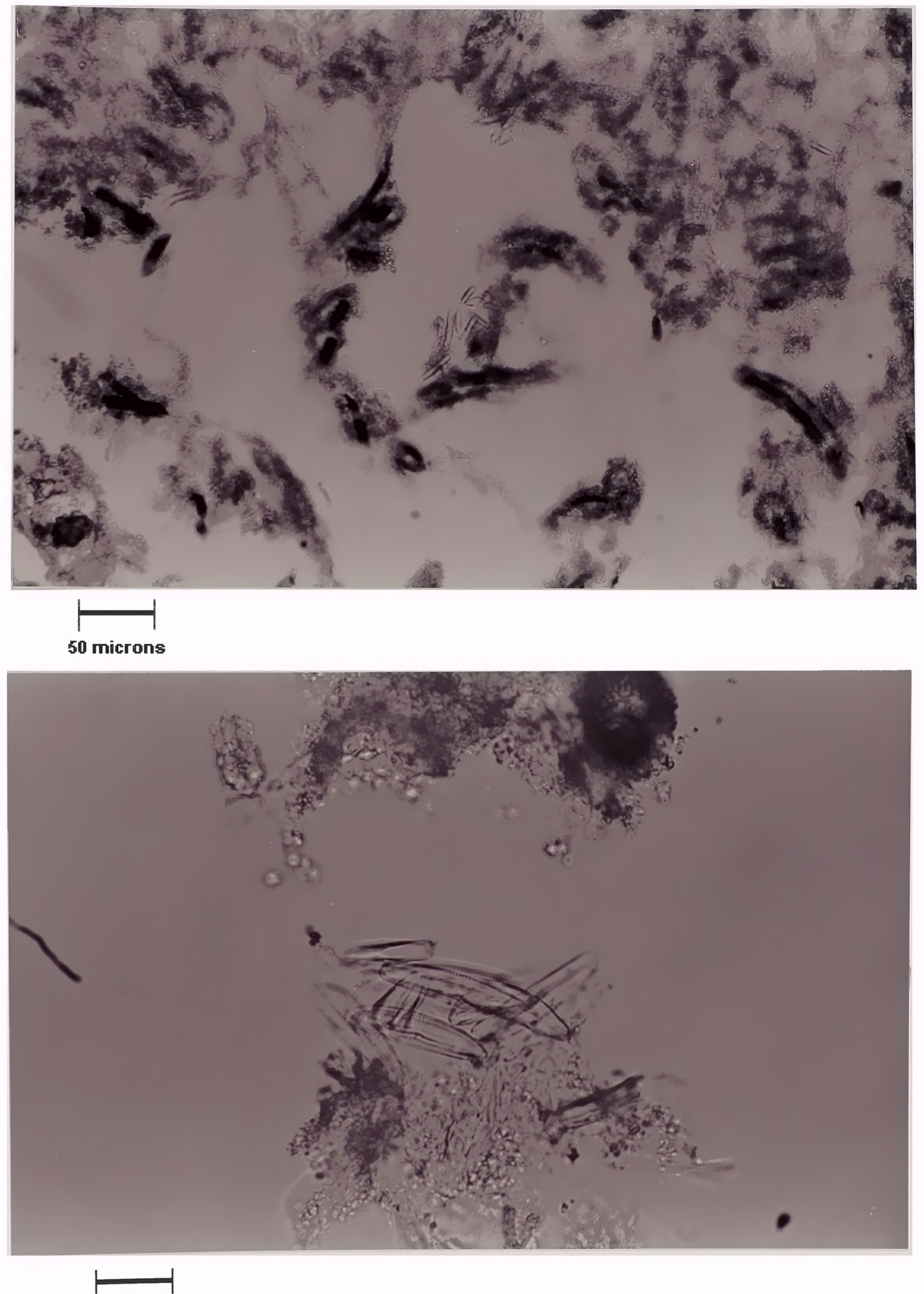

25 microns 